Nota añadida / added note: 23-07-2021

Ver fe de erratas al final de este artículo y en / See erratum at the end of this paper and at

http://dx.doi.org/10.22201/cgeo.20072902e.2021.2.1647

\title{
Fauna de tiburones y rayas de la Formación Tirabuzón (Plioceno) en el Cañón El Álamo, sierras de La Reforma - El Aguajito, Baja California Sur, México
}

\section{R. Marcela Lira-Beltrán",*, Gerardo González-Barba², José Luis Macías³, Azucena Solis-Añorve², Felipe García-Tenorio ${ }^{3}$, Laura García-Sánchez ${ }^{1}$ y Susana Osorio-Ocampo ${ }^{1}$}

\author{
${ }^{1}$ Posgrado en Ciencias de la Tierra, ENES Morelia, Universidad Nacional Autónoma de México, \\ Antigua Carretera a Pátzcuaro No.8701, Ex Hacienda de San José de la Huerta, C.P. 58190, Morelia, Michoacán, México. \\ ${ }^{2}$ Museo de Historia Natural, Universidad Autónoma de Baja California Sur, \\ Carretera al sur Km. 5.5, Colonia El Calandrio, C.P. 23080, La Paz, B.C.S., México. \\ ${ }^{3}$ Instituto de Geofísica, Unidad Michoacán, Universidad Nacional Autónoma de México, \\ Antigua Carretera a Pátzcuaro No.8701 Col. Ex Hacienda de San José de la Huerta, C.P.58190 Morelia, Michoacán, México. \\ *marcelalirabeltran@gmail.com
}

\section{RESUMEN}

En el presente trabajo presentamos los resultados de un estudio estratigráfico y paleontológico de nuevas localidades fosilíferas encontradas en el sustrato de las calderas La Reforma y El Aguajito, ubicadas aproximadamente a $30 \mathrm{~km}$ al norte de la población de Santa Rosalía, Baja California Sur, México. La sucesión sedimentaria estudiada se correlaciona con la Formación Tirabuzón del Plioceno de la cuenca de Santa Rosalía y forma parte del sustrato sedimentario de las calderas pleistocénicas. Una de las secciones más completas se encuentra expuesta en el cañón El Álamo y consiste en una sucesión de arenisca limosa de color naranja, conglomerado con abundantes fósiles de dientes de tiburón y rayas, un depósito volcánico basal y limolita de color amarillo ocre, las cuales en este trabajo se agruparon en tres unidades: 1) arenisca-limolita naranja, 2) depósito volcánico basal y 3) limolita Cimarrón. El material fósil estudiado consiste en 500 ejemplares de dientes individuales de elasmobranquios (macrodientes) que se extrajeron in situ. Para la localidad de El Álamo reportamos 19 taxa de tiburones y siete de rayas, siendo así el primer reporte de una fauna de Batoideos para la Formación Tirabuzón. La misma sucesión litológica y fósil fue encontrada en otras cinco localidades: Corkscrew Hill, Santa María, Cueva Amarilla, El Morro Prieto y El Gringo, en donde reportamos la presencia de Hemipristis Serra, así como Otodus megalodon y Parotodus benedeni para la localidad de Corkscrew Hill. Sobreyaciendo discordantemente a la unidad limolita Cimarrón se encuentra la ignimbrita Cueva Amarilla de la Formación Infierno fechada en 2.4 Ma. Estas nuevas localidades son una herramienta para poder correlacionar la Formación Tirabuzón hasta la porción noroccidental de la Caldera El Aguajito. El ensamblaje faunístico reportado corresponde a un ambiente marino somero de plataforma continental de aguas tropicales de edad Plioceno medio-superior.

Palabras clave: Neógeno; Elasmobranquios; Formación Tirabuzón; cuenca de Santa Rosalía; Baja California Sur; México.

\begin{abstract}
In this paper we present the results of a stratigraphic and paleontological study of new fossil localities found in the La Reforma and El Aguajito Calderas, Baja California Sur, Mexico, approximately $30 \mathrm{~km}$ north of the town of Santa Rosalía. The studied sedimentary succession is part of the substrate of the Pleistocene Calderas and is related to the Tirabuzón Formation (Pliocene) of the Santa Rosalía basin. During the Pliocene-Pleistocene the boundary of the Santa Rosalia basin extended beyond these volcanic structures and therefore the El Alamo canyon site recorded stratigraphic and paleontological evidences of the Tirabuzon Formation with abundant shark teeth and ray fossils and interbedded volcanic deposits. Shark fauna had previously been reported for the Tirabuzón Formation, to the south of the study area, but not at the El Álamo canyon. The same lithology and fossil assemblage was found in other locations: Corkscrew Hill, Santa María, Cueva Amarilla, El Morro Prieto and El Gringo. The studied material consists of 500 individual specimens of elasmobranch fossil teeth (macroteeth). We report 17 species and two genera of sharks, one species, and six genera of rays and, for the first time, a Batoid fauna for the Tirabuzón Formation. Discordantly on top of the Cimarrón siltstone appears the 2.4 Ma Cueva Amarilla ignimbrite of the Inferno Formation. The faunal assembly corresponds to a shallow and warm marine environment, similar to the current fauna of the Eastern Tropical Pacific.
\end{abstract}

Key words: Neogene; Elasmobranch; Tirabuzón Formation; Santa Rosalia basin; Baja California Sur; Mexico.

\section{INTRODUCCIÓN}

El proceso de apertura del Golfo de California, ocurrido a partir del Mioceno tardío (Oskin y Stock, 2003; Bennett et al., 2013), originó una serie de cuencas sedimentarias de tipo "pull-apart" y extensionales que son el resultado de la etapa de "rifting" temprano y de fallamiento

Lira-Beltrán, R.M., González-Barba, G., Macías, J.L., Solis-Añorve, A., García-Tenorio, F., García-Sánchez, L., Osorio-Ocampo, S., 2020, Fauna de tiburones y rayas de la Formación Tirabuzón (Plioceno) en el Cañón El Álamo, sierras de La Reforma - El Aguajito, Baja California Sur, México: Revista Mexicana de Ciencias Geológicas, v. 37, núm. 1, p. 40-63. 
normal dextral oblicuo en dirección NNW (Dorsey y Umhoefer, 2012). Las cuencas que se ubican en el borde oeste del Golfo de California son de tipo marginal donde domina el fallamiento transtensional, siendo las más importantes las de San José del Cabo, Loreto y Santa Rosalía (Dorsey y Umhoefer, 2012). La cuenca de Santa Rosalía (SR) está localizada en la región centro oriental de la Península de Baja California, tiene una extensión aproximada de $60 \mathrm{~km}$ y se extiende desde la localidad de San Bruno hasta el borde sur de la Caldera la Reforma (Figura 1a). Esta cuenca comprende más de 500 metros de espesor de sedimentos marinos y continentales (Ochoa-Landín et al., 2000). Las secuencias sedimentarias que rellenan la cuenca de SR fueron descritas y estudiadas por Wilson (1948) en los alrededores del poblado de Santa Rosalía y del distrito minero del Boleo. Wilson (1948), describió discordancias y megafauna marina con base en la cual dividió la secuencia en cuatro formaciones que, de la más antigua a la más joven son: Formación Boleo, Formación La Gloria (actualmente Formación Tirabuzón), Formación Infierno y Formación Santa Rosalía. La extensión de las formaciones mencionadas no está bien definida hacia las calderas de El Aguajito y La Reforma, ya que el límite norte de la cuenca de SR no está bien establecido. Algunos autores extienden la cuenca hasta la Caldera de La Reforma (Ortlieb y Colletta, 1984) y por debajo del campo volcánico Tres Vírgenes (Garduño-Monroy et al., 1993) dado que estas formaciones fueron descritas en los pozos perforados por la Comisión Federal de Electricidad entre los 500 y $900 \mathrm{~m}$ de profundidad (Verma et al., 2006; Viggiano-Guerra et al., 2009). A pesar de estas menciones no se había realizado un estudio estratigráfico ni paleontológico detallado de las secuencias marinas en las calderas de El Aguajito y La Reforma que permitiera su correlación con las formaciones de la cuenca de SR. Esta falta de información no es casual dado que la zona de estudio es muy abrupta y no presenta rutas de acceso a ella. Con la finalidad de definir la edad de la sucesión sedimentaria en esta región y su correlación con las formaciones sedimentarias de la cuenca, llevamos a cabo un estudio estratigráfico y paleontológico detallado. En la región describimos 60 secciones estratigráficas y su correlación litoestratigráfica, enfocándonos en la sucesión descrita que aflora en el cañón El Álamo (Figura 1, localidad 5), apoyándose además en secciones levantadas en otras cinco localidades más que soportan esta correlación. En la sección del cañón El Álamo se pueden observar las relaciones estratigráficas entre los depósitos volcánicos pleistocénicos, producto de la evolución de las calderas, y las rocas volcanosedimentarias del Plioceno-Pleistoceno que en este sitio tienen más de $200 \mathrm{~m}$ de espesor. En el presente trabajo presentamos evidencias paleontológicas, litológicas y paleoambientales que permiten correlacionar estos depósitos sedimentarios marinos con la Formación Tirabuzón de la cuenca de SR.

\section{ANTECEDENTES}

En la zona de estudio se han realizado algunos trabajos sobre la estratigrafía volcanosedimentaria y la geotermia (Garduño-Monroy et al., 1993, Verma et al., 2006, Viggiano-Guerra et al., 2009, Avellan et al., 2018; García-Sánchez et al., 2019, Osorio-Ocampo et al., 2019). Garduño-Monroy et al. (1993) estudiaron la caldera El Aguajito, localizada al NW del cañón El Álamo, y en su trabajo mencionan que la caldera La Reforma y el complejo volcánico Tres Vírgenes se localizan en una depresión orientada NW-SE, que representa la prolongación NW de la cuenca de Santa Rosalía y que es controlada

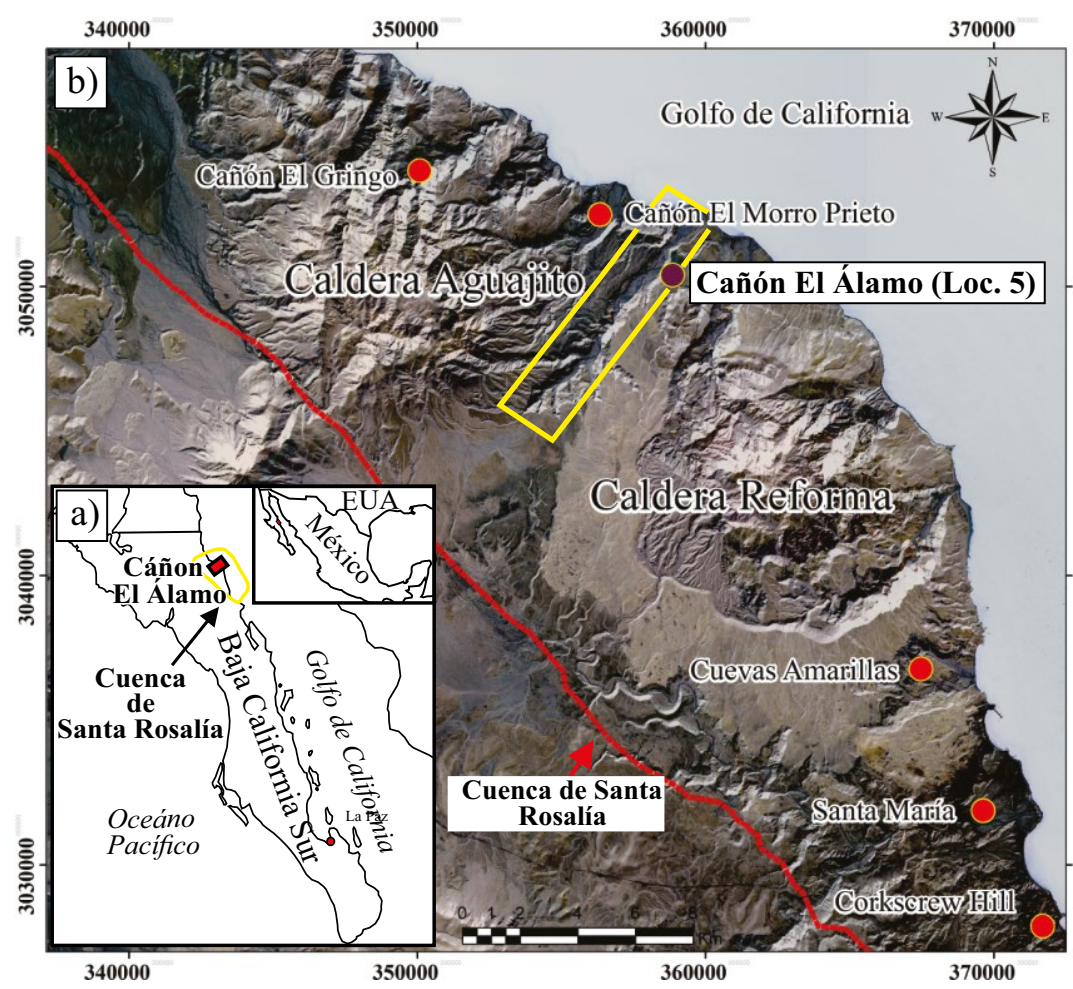

Figura 1. Ubicación del cañón El Álamo (Loc. 5) y otras cinco localidades fosilíferas discutidas en el texto. a) Mapa regional, donde se observa la localización de la cuenca de Santa Rosalía y del Cañón El Álamo. b) Ubicación de las localidades de Corkscrew Hill, Santa María, Cuevas Amarillas, cañón El Álamo, cañón El Morro Prieto y cañón El Gringo. El cañón El Álamo (recuadro amarillo) se localiza entre las calderas La Reforma y El Aguajito; la línea roja indica el límite de la cuenca de Santa Rosalía. Mapa realizado con base en imágenes pancromáticas y multiespectrales SPOT6-7 (Satellite Pour I'Observation de la Terre), con resoluciones de $1.5 \mathrm{~m}$ y $6 \mathrm{~m}$, respectivamente. 
por estructuras extensionales relacionadas con el Golfo de California. Estos autores concluyeron que en el cañón El Álamo se observa la relación estratigráfica entre los depósitos volcánicos de las calderas La Reforma y El Aguajito, ambas estructuras emplazadas sobre depósitos marinos con coquinas y areniscas probablemente del Plioceno (Garduño-Monroy et al., 1993). En cambio, la cuenca de SR ha sido ampliamente estudiada por diversos autores por albergar depósitos de cobre de interés económico dentro de la Formación Boleo. Esta cuenca consiste de depósitos sedimentarios marinos de edad Mioceno tardío a Pleistoceno (Wilson 1948; Wilson y Veytia, 1949; Wilson y Rocha, 1955; Ortlieb y Colletta, 1984, Holt et al., 2000, Ochoa-Landín et al., 2000; Holt et al., 2000) relacionados con el proceso de apertura del Golfo de California. Las formaciones que componen la cuenca son Formación Boleo (Mioceno tardío), Formación La Gloria (PliocenoPleistoceno superior), Formación Infierno (Pleistoceno superior) y Formación Santa Rosalía (Pleistoceno). Wilson y Veytia (1949) y Wilson y Rocha (1955) describieron a la Formación Boleo como una gruesa sucesión de conglomerados, calizas fosilíferas, capas de yeso y en menor proporción areniscas fosilíferas, con espesores que varían de 50 a 250 metros. Holt et al. (2000) obtuvieron una edad de 6.57-6.94 Ma con el método ${ }^{40} \mathrm{Ar} /{ }^{39} \mathrm{Ar}$ y magnetoestratigrafía para una pequeña intercalación de material volcánico conocido como "Cinta Colorada", por lo que sugieren una edad probable de 6.93-7.09 Ma para la base y de 6.14-6.27 Ma para la cima de la formación. La Formación La Gloria corresponde a una secuencia de arenisca y conglomerado del Plioceno medio con espesor promedio de $60 \mathrm{~m}$ (Wilson y Rocha, 1955), que se encuentra sobreyacida discordantemente por arenisca fosilífera y conglomerado de la Formación Infierno. La Formación Infierno tiene un espesor promedio de $50 \mathrm{~m}$ y se caracteriza por ser mucho más fosilífera que la Formación La Gloria, por lo tanto, el contenido fósil puede ser una buena herramienta para distinguir estas dos formaciones (Wilson y Rocha, 1955). Se ha reportado que en las cercanías de la caldera La Reforma, la Formación Infierno se encuentra interestratificada con capas de toba y fragmentos de pómez (Ortlieb y Colletta, 1984). La rocas sedimentarias más recientes corresponden a la Formación Santa Rosalía y consisten en un conglomerado calcáreo que no sobrepasa los $15 \mathrm{~m}$ de espesor y que por lo general se encuentra coronando mesas. Esta formación presenta características litoestratigráficas similares a depósitos de terrazas marinas (Ortlieb, 1981; Ortlieb y Colletta, 1984).

A continuación se describe más detalladamente la Formación La Gloria, objeto del presente trabajo. La Formación La Gloria corresponde a secuencias de arenisca y conglomerado del Plioceno medio con espesores mayores a 180 m (Wilson 1948; Wilson y Veytia, 1949; Wilson y Rocha, 1955). La litología más característica de la Formación La Gloria corresponde a una arenisca fosilífera con espesores que alcanzan más de $100 \mathrm{~m}$ (Wilson y Rocha, 1955). La arenisca tiende a gradar hacia la costa del Golfo de California a limolita masiva y lutita con vetas de yeso y se acuñan tierra adentro, indicando probablemente la antigua línea de costa (Wilson y Rocha, 1955). La arenisca de la Formación La Gloria contiene fósiles marinos, los cuales se pueden encontrar bien preservados. Los fósiles más abundantes corresponden a pectínidos, ostreas y localmente equinodermos; con base en la fauna marina se estableció una edad de Plioceno medio (Wilson y Rocha, 1955). Carreño (1981) reportó una fauna de foraminíferos y ostrácodos de edad Plioceno temprano-medio para la base y de Plioceno mediotardío para la cima de la formación. De acuerdo con Carreño (1981), la microfauna encontrada se caracteriza por ser una mezcla de aguas cálidas y frías en un ambiente de mar abierto con profundidades máximas entre 200 a 500 m, con influencia de terrígenos marginales. En este mismo trabajo Carreño propone cambiar el nombre de Formación La Gloria asignado por Wilson (1948), a Formación Tirabuzón, nombre que usamos en este trabajo. Applegate (1978) reportó en la cuenca de
SR algunas localidades fosilíferas con abundantes dientes de tiburón asociadas con los depósitos de la Formación Tirabuzón. Este autor estudió una fauna de tiburones colectados en la localidad de Loma de Tirabuzón o "Corkscrew Hill" localizada a $5 \mathrm{~km}$ al norte de la población de Santa Rosalía, en donde identificó 29 taxones (Tabla 1), siendo los más representativos Carcharhinus, Sphyrna y Otodus. Con esta fauna de tiburones, Applegate (1978) estableció una edad de Plioceno medio y condiciones paleoambientales de mar abierto, con profundidades que oscilaban de 10 a $100 \mathrm{~m}$.

\section{MATERIAL Y MÉTODOS}

El material estudiado consiste de 500 ejemplares de dientes fósiles individuales de elasmobranquios que fueron obtenidos por tamizado y colectados manualmente in situ en afloramientos de las localidades cañón El Álamo (Loc. 5), Corkscrew Hill, Santa María, Cuevas Amarillas, Morro Prieto y Gringo (Figura 1), durante cuatro campañas de campo realizadas entre 2016 y 2018. El material fósil se depositó en el Museo de Historia Natural de la Universidad Autónoma de Baja California Sur (MHN-UABCS) y en el Laboratorio de Análisis de Partículas y Separación de Minerales del Instituto de Geofísica, Unidad Michoacán, de la Universidad Nacional Autónoma de México (IGUM-UNAM).

Para la localidad cañón El Álamo (Loc. 5) que se ubica en las coordenadas X: 357711, Y: 3049890 se tomó una muestra de 10 kilos de material sedimentario fosilífero, la cual fue tamizada y lavada en el laboratorio. Con ese método se lograron recuperar microdientes y dentículos dérmicos de tiburones y rayas en las fracciones de 1190 y 354 micras, para posteriormente analizase y fotografiarse con el microscopio electrónico de barrido Tabletop microscope modelo TM3030 Plus marca Hitachi. Las medidas fueron tomadas a lo largo (incluyendo la raíz) y ancho de cada ejemplar. La clasificación taxonómica se realizó con base en una extensa revisión bibliográfica (Compagno, 1984a; Compagno, 1984b; Compagno, 2001; Compagno et al., 2005; Cappetta, 2012) y realizando la comparación con ejemplares actuales y fósiles de la colección del MHN-UABCS.

\section{GEOLOGÍA Y ESTRATIGRAFÍA}

En esta sección se hace una descripción de las características litológicas y estratigráficas, así como de los aspectos paleontológicos relevantes de la localidad cañón El Álamo (Loc. 5) y en cuatro secciones localizadas en las calderas La Reforma (localidades de Santa María y Cuevas Amarillas) y El Aguajito (localidades El Morro Prieto y El Gringo), así como en una sección cercana a la población de Santa Rosalía (localidad de Corkscrew Hill) importante para poder establecer la correlación estratigráfica.

\section{Cañón El Álamo}

La zona de estudio en parte comprende un área rectangular en dirección NE-SO a lo largo del cañón El Álamo (Figura 1), el cual separa morfológicamente a las calderas de El Aguajito y La Reforma (Garduño-Monroy et al., 1993). La sucesión sedimentaria que aflora en la base del cañón está representada por una limolita de color amarillo ocre poco fosilífera con un espesor promedio de 30 metros, la cual se presenta en afloramientos aislados desde la línea de costa hasta el fondo del cañón ( $~ 9 \mathrm{~km}$ de extensión). El afloramiento más completo de rocas sedimentarias marinas relacionadas con la Formación Tirabuzón se encontró en la localidad cañón El Álamo (Loc. 5; Figura 1), en donde se levantó una columna estratigráfica de $27 \mathrm{~m}$ de espesor (Figura 2). La litología está conformada de la base a la cima por arenisca, limolita are- 


\section{Sección compuesta}

Sucesión volcano-sedimentaria
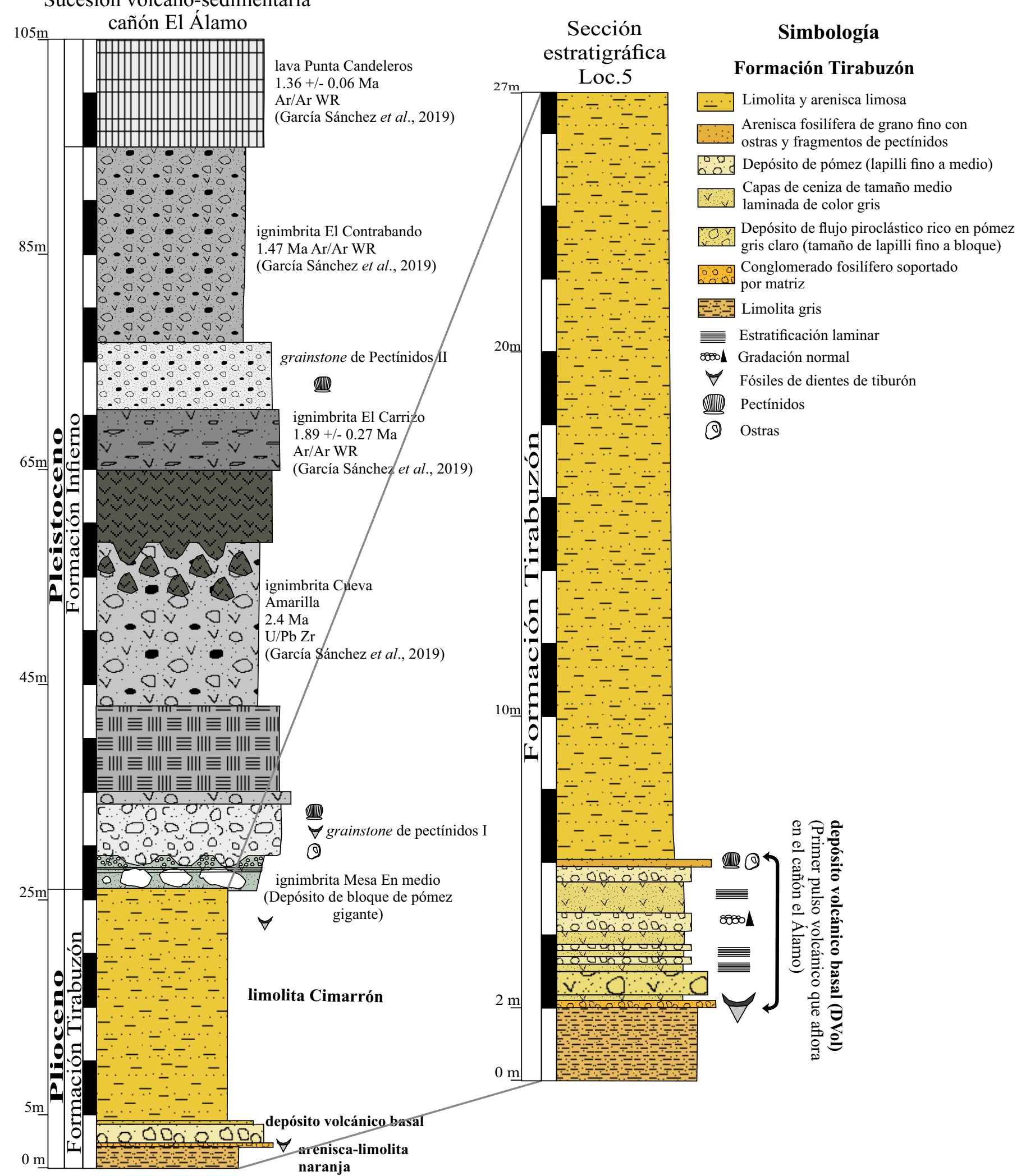

Figura 2. Sección estratigráfica compuesta de la sucesión volcanosedimentaria expuesta en el cañón El Álamo y su correlación con la sección estratigráfica de la localidad 5, donde se colectó el material estudiado. 
nosa, conglomerado fosilífero, depósitos volcánicos, arenisca fosilífera y limolita, las cuales se agruparon dentro de tres unidades informales con base a sus características litológicas y el contenido fósil: areniscalimolita Naranja (Ar-LiN), depósito Volcánico Basal (DVol) y limolita Cimarrón (LiC). En general, esta sucesión se caracteriza por presentar un conglomerado con fósiles de dientes de tiburones, rayas y de peces óseos, fauna que han sido reportada con anterioridad en sedimentos marinos del Plioceno medio de la Formación Tirabuzón (Applegate, 1978). A continuación, se presenta una descripción detallada de estas unidades, desde la más antigua a la más reciente:

1) Arenisca-limolita naranja (Ar-LiN). Se caracteriza por presentar en la base una limolita arenosa y en la cima un horizonte de conglomerado. La limolita arenosa es de color café claro a gris, con un espesor promedio de dos metros, presenta estratificación paralela difusa y no se encontraron fósiles, esta sobreyacida por un conglomerado polimíctico fosilífero de 15 a $20 \mathrm{~cm}$ de espesor, mal seleccionado y con cementante carbonatado. Los clastos son de origen sedimentario (limolita, arenisca limosa), bioclastos representados principalmente por fragmentos de erizos, quelas de cangrejo y dientes de tiburón, nódulos de fosforita, dolomita y ankerita. En la cima se observan lentes de limolita color café claro de hasta $3 \mathrm{~cm}$ de espesor. Dentro del conglomerado se colectaron fósiles de dientes de tiburón y rayas (Figura 3a-3d). También se encontraron foraminíferos, quelas de cangrejos, moldes internos de bivalvos, braquiópodos, dientes y vertebras de peces óseos, espinas de rayas y dentículos dérmicos de tiburones y rayas.

2) Depósito volcánico basal (DVol). Corresponde a un depósito de flujo piroclástico enriquecido en pómez de color beige a amarillo claro con espesor de $2.5 \mathrm{~m}$. En la base se presenta una capa de pómez
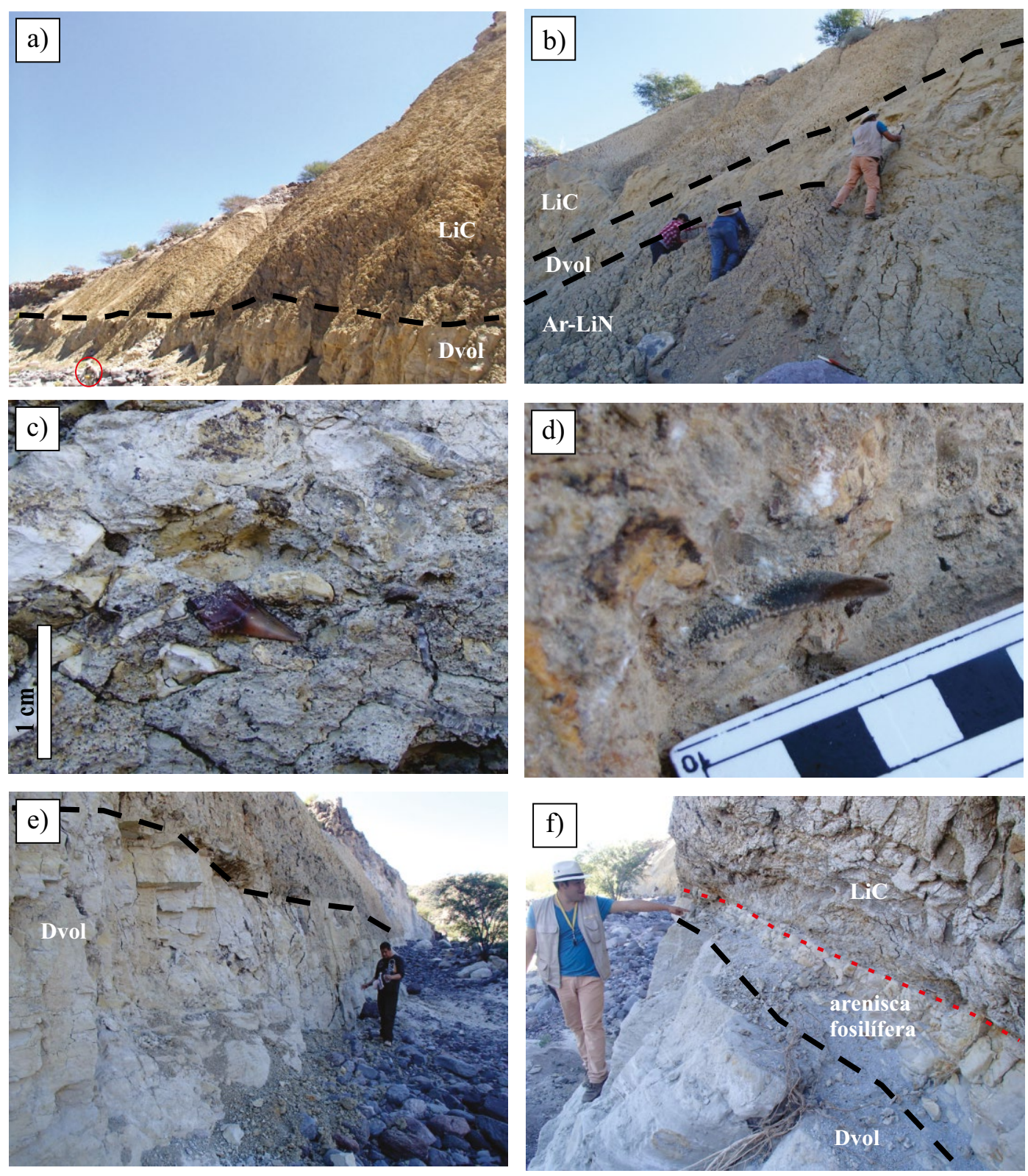

Figura 3. Afloramientos en la localidad cañón El Álamo (Loc. 5). a) Contacto entre las unidades depósito volcánico basal (Dvol) y limolita Cimarrón (LiC). b) Contacto entre las unidades arenisca y limolita naranja ( $\mathrm{Ar}-\mathrm{LiN}$ ), depósito volcánico basal (Dvol) y limolita Cimarrón (LiC). c) conglomerado fosilífero y diente de C. albimarginatus. d) Diente de Carcharodon charcharias. e) Unidad depósito volcánico basal. f) En la base de la unidad LiC se encuentra una arenisca fosilífera. 
del tamaño de lapilli a bloque inmersos en una matriz de ceniza. En la sección superior domina la alternancia de capas de ceniza con estratificación laminar marcada (Figura 3e) y capas de pómez de color gris claro.

3) Limolita Cimarrón (LiC). Esta unidad presenta en su base una arenisca de grano fino a limosa fosilífera con fragmentos de pectínidos y ostras (Figura 3f). La litología más característica es una limolita a limolita arenosa de color amarillo ocre a café claro, con estratificación laminada marcada a difusa. La LiC es de grano muy fino, no se distinguen minerales a simple vista, es moderadamente deleznable y está fracturada, presenta un espesor de $21 \mathrm{~m}$. Por lo general, la LiC es poco fosilífera, sin embargo, se han encontrado dientes de tiburón bien preservados en la base de la unidad en las localidades del cañón del Morro Prieto y cañón El Gringo a 4.5 y 9 km al norte del cañón El Álamo.

En el cañón El Álamo se puede observar que la unidad limolita Cimarrón está sobreyacida por rocas volcanosedimentarias relacionada con la Formación Infierno (Pleistoceno) y por depósitos volcánicos de las calderas la Reforma y el Aguajito (Osorio-Ocampo et al., 2019). La sucesión volcanosedimentaria de la Formación Infierno tiene un espesor de más de $70 \mathrm{~m}$ (Figura 2) y está conformada por siete unidades informales ignimbrita Mesa En medio, grainstone de Pectínidos I, ignimbrita Cueva Amarilla, ignimbrita El Carrizo, grainstone de Pectínidos II, ignimbrita El Contrabando y lava Punta Candeleros. García-Sánchez et al. (2019) fecharon con el método de ${ }^{40} \mathrm{Ar} /{ }^{39} \mathrm{Ar}$ en roca total las siguientes unidades: ignimbrita El carrizo en $1.89 \mathrm{Ma}$, ignimbrita El Contrabando en 1.47 Ma y lava Punta Candeleros en $1.36 \mathrm{Ma}$, las cuales se muestran en la sección compuesta del cañón El Álamo (Figura 2). Estos mismos autores obtuvieron una fecha de $2.4 \mathrm{Ma}$ mediante el método de $\mathrm{U} / \mathrm{Pb}$ en circones de la ignimbrita Cueva Amarilla, que en la localidad del mismo nombre se encuentra sobreyaciendo directamente a la unidad LiC.

\section{Otras localidades}

Para poder realizar la correlación de la Formación Tirabuzón, se levantaron secciones estratigráficas en cinco localidades de interés geológico y paleontológico: Corkscrew Hill, Santa María y Cueva Amarilla al sur del borde caldérico de La Reforma y localidades cañón El Morro Prieto y cañón El Gringo en la caldera El Aguajito.

En la localidad de Corkscrew Hill, se levantó una sección estratigráfica de $70 \mathrm{~m}$ de espesor. La litología se caracteriza por una arenisca limosa en la base de color café claro con lentes de arenisca con fósiles de ostras y pectínidos principalmente. Esta capa está sobreyacida por una arenisca de grano medio de color naranja rojizo con icnofósiles del tipo gyrolithes, que pueden alcanzar hasta $2 \mathrm{~m}$ de longitud. Le sigue una arenisca de grano fino a medio bien seleccionada de color café claro, muy fosilífera, y de aproximadamente $3 \mathrm{~m}$ de espesor. Los fósiles más abundantes corresponden a dientes de tiburón, rayas, peces y huesos de mamíferos marinos (cetáceos); también se pueden presentar moldes internos de gasterópodos y bivalvos, vértebras de peces, espículas de erizo y fragmentos de espinas de rayas. Finalmente, coronando la secuencia se presenta una limolita poco fosilífera de color amarillo ocre a café claro que corresponde con la unidad limolita Cimarrón, descrita en la localidad 5 del cañón El Álamo.

En las otras localidades se levantaron secciones estratigráficas de la Formación Tirabuzón con espesores de 23 m en Santa María, 46 m en Cuevas Amarillas, $36 \mathrm{~m}$ en la localidad de cañón El Morro Prieto y de $21 \mathrm{~m}$ en el cañón El Gringo, observándose que la litología es muy similar, en todas las localidades. Esta se caracteriza de la base a la cima por una secuencia de arenisca limosa de color café claro, arenisca fosilífera de color naranja rojizo y una limolita de color amarillo ocre a café claro hacia la cima de la secuencia (unidad LiC). Las capas fosilíferas presentan pectínidos, ostras, moldes internos de gasterópodos y bivalvos, dientes de tiburón y de rayas, fragmentos y espículas de erizos, dientes de peces y fragmentos de huesos de ballena.

\section{PALEONTOLOGÍA SISTEMÁTICA}

Dentro de este apartado se realiza una breve descripción de los principales elasmobranquios colectados en la unidad arenisca y limolita naranja de la localidad cañón El Álamo (Loc. 5) (Tabla 2), los cuales están representados por 19 taxa de tiburones y siete de rayas. La clasificación taxonómica está basada en Capetta (2012), incluyendo los autores de las determinaciones taxonómicas.
Squaliformes Compagno, 1973
Centrophoridae Bleeker, 1859
Deania Jordan y Snyder, 1902
Deania cf. calcea (Lowe, 1839)

Ejemplares referidos. MHN-UABCS/SR/MICDC1 (Figura 4a), MHN-UABCS/SR/MICDC2 (Figura 4b), MHN-UABCS/SR/MICDH1 (Figura 4c) y MHN-UABCS/SR/MICDH2 (Figura 4d).

Localidad y edad. Cañón El Álamo (Loc. 5), calderas El Aguajito y La Reforma, BCS, México. Formación Tirabuzón (Plioceno).

Descripción. MHN-UABCS/SR/MICDC1 corresponde a un diente superior de alto $1.9 \mathrm{~mm}$ y ancho $2.05 \mathrm{~mm}$, MHN-UABCS/SR/MICDC2 es un diente inferior de alto $2.1 \mathrm{~mm}$ y ancho $2.6 \mathrm{~mm}$, MHN-UABCS/ $\mathrm{SR} / \mathrm{MICDH} 1$ es un diente inferior de alto $1.8 \mathrm{~mm}$ y ancho $1.7 \mathrm{~mm}$ y MHN-UABCS/SR/MICDH2 corresponde a un diente inferior de alto $2 \mathrm{~mm}$ y ancho de $2.5 \mathrm{~mm}$. Los dientes presentan principalmente las coronas, las raíces están incompletas. Las coronas son diagnósticas en la cara labial por presentar un delantal (apron) el cual es una prolongación de la corona esmaltada sobre la raíz. La cara lingual se caracteriza por presentar una úvula, la cual es una prominencia de la corona en su parte basal.

Observaciones. El Orden Squaliformes es un grupo muy diverso de tiburones cosmopolitas que se pueden encontrar actualmente en aguas tropicales y templadas frías costeras y oceánicas profundas. El género Deania está caracterizado por dientes inferiores menores a $5 \mathrm{~mm}$ de ancho. La raíz es estrecha y tiene en su cara basal dos orificios axiales, separados y fuera de línea con la úvula, los forámenes margino-labiales están generalmente bien desarrollados a cada lado de la base del delantal o prolongación de la corona (Cappetta, 2012). Los tiburones del género Deania típicamente se encuentra en plataforma continental externa, pero se puede encontrar en plataformas insulares, generalmente en el fondo o cerca de él (Compagno et al., 2005; Ebert et al., 2016). La dentición de los especímenes en este documento, presenta una morfología similar a la especie Deania calcea (Lowe, 1839) como se muestra en Herman et al. (1989), la cual presenta una amplia distribución templada casi global, en la plataforma continental de América del sur desde la Tierra del Fuego hasta Perú (Ebert et al., 2016). La especie Deania calcea no cuenta con registros en la costa del Pacífico de Norte América. Por lo que podemos inferir que al menos durante el Plioceno, esta especie tuvo una distribución en el Golfo de California.

\section{Squalidae Bonaparte, 1834 Squalus Linnaeus, 1758 Squalus sp.}

Ejemplares referidos. MHN-UABCS/SR/MICS1 (Figura 4e). Localidad y edad. Cañón El Álamo, calderas El Aguajito y La Reforma, BCS, México. Formación Tirabuzón (Plioceno). 


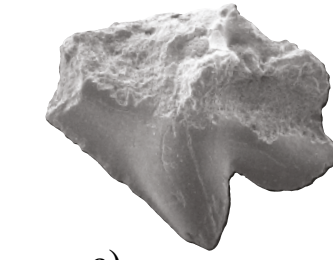

a)

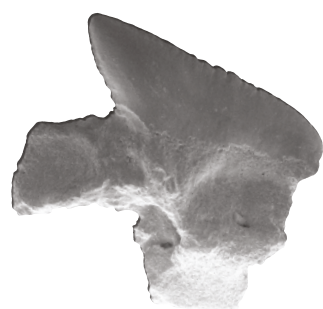

b)

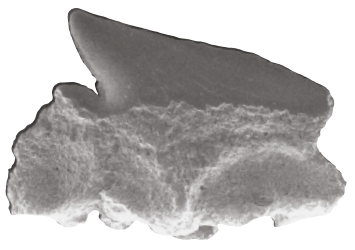

c)

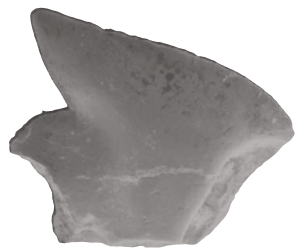

d)

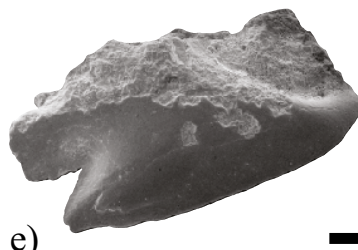

e)
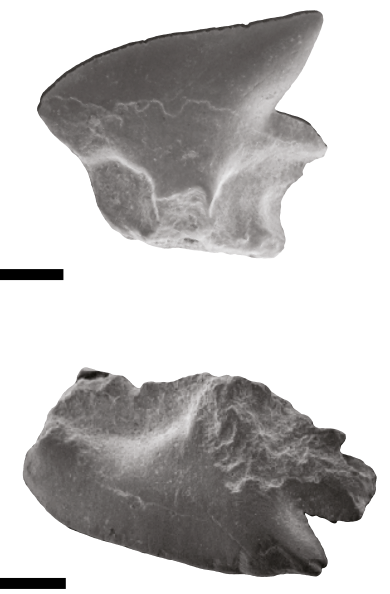

Figura 4. Dientes fósiles de las familias Centrophoridae y Squalidae. a) Deania cf. Calcea (MHN-UABCS/SR/MICDC1). Diente superior posterior, vistas labial y lingual. b) Deania cf. calcea (MHN-UABCS/SR/MICDC2). Diente inferior anterior, vistas lingual y labial. c) Deania cf. calcea (MHN-UABCS/SR/ MICDH1). Diente inferior lateral, vistas lingual y labial. d) Deania cf. calcea (MHN-UABCS/SR/MICDH2). Diente inferior lateral, vistas lingual y labial. e) Squalus sp. (MHN-UABCS/SR/MICS1). Diente superior lateral, vistas lingual y labial. Escala igual a $1 \mathrm{~mm}$

Descripción. MHN-UABCS/SR/MICS1 es un diente superior de alto $1.7 \mathrm{~mm}$ y de ancho $3.25 \mathrm{~mm}$. El diente está comprimido labiolingualmente, la cúspide es triangular, desplazada marcadamente hacia atrás. El talón distal es corto pero muy alto y con una línea convexa hacia fuera; el filo mesial es liso. La corona posee un delantal medio labial de longitud con bordes paralelos y una úvula medio-lingual más o menos larga. La raíz está comprimida y no muy alta, su cara basal es plana o ligeramente cóncava.
Observaciones. El género Squalus se conoce como fósil solo en dientes aislados y algunas espinas de las aletas, tienen una morfología muy similar en ambas mandíbulas; los dientes inferiores son notablemente más grandes, de hasta $5 \mathrm{~mm}$ de ancho. El género generalmente habita en plataformas y taludes continentales e insulares, en aguas templadas (Compagno et al., 2005; Ebert et al., 2016). En el registro fósil el género Squalus tiene una distribución desde el Cretácico Superior hasta el reciente (Cappetta, 2012). Squalus aff. blainvillei (Risso, 1826) del Plioceno de Argens en Francia y Alba en Italia (Cappetta y Nolf, 1991; Cappetta y Cavallo, 2006). Purdy et al. (2001) registró a Squalus sp. del Plioceno en la Formación Yorktown en la mina de Lee Creek en Carolina del Norte. Kent (2018) describe dos formas dentales como Squalus sp.1 y Squalus sp. 2, del Mioceno de la Formación Calvert en Virginia. Squalus acanthias Linnaeus (1758) es una especie cosmopolita que se encuentra en aguas templadas, antitropicales incluyendo la porción occidental de la península de Baja California (Compagno, 2016). La morfología dental del espécimen de El Álamo coincide con la de la última especie $S$. acanthias mostrada por Herman et al. (1989). Aunque recientemente Ebert et al. (2010) resucitaron la especie Squalus suckleyi (Girard, 1855) para la población del Pacifico Norte, utilizando datos merísticos, morfológicos y moleculares.

\author{
Squatiniformes Buen, 1926 \\ Squatinidae Bonaparte, 1838 \\ Squatina Duméril, 1806 \\ Squatina californica Ayres, 1859
}

Ejemplares referidos. MHN-UABCS/SR/MDS1 (Figura 5a); MHNUABCS/SR/MDS2 (Figura 5b).

Localidad y edad. Cañón El Álamo (Loc. 5), calderas El Aguajito y La Reforma, BCS, México. Formación Tirabuzón (Plioceno).

Descripción. Los ejemplares estudiados de $S$. californica tienen las siguientes dimensiones: MHN-UABCS/SR/MDS1 tiene de alto $2.9 \mathrm{~mm}$ $\mathrm{y}$ ancho $3.43 \mathrm{~mm}$ y MHN-UABCS/SR/MDS2 tiene de alto $2.47 \mathrm{~mm}$ y ancho $3.2 \mathrm{~mm}$. Los ejemplares presentan una raíz de contorno triangular aplanada, convexa proyectándose hacía la cara lingual y una corona con forma de cúspide triangular, delgada proyectada verticalmente la cual es típica de la especie del género.

Observaciones. El género Squatina es conocido generalmente por dientes aislados en depósitos mesozoicos y cenozoicos, aunque Cabrera et al. (2012) describieron elementos mandibulares encontrados en la Formación Puerto Madryn del Mioceno de Argentina. La dentición del género es muy estable a lo largo del tiempo y la separación de especies basada solo en dientes aislados por lo general es difícil debido a que son muy similares (Capetta, 2012). Una comparación dental morfológica de los especímenes de la localidad de El Álamo coincide en su morfología con los ejemplares de Squatina squatina Linnaeus, 1758 del Mar del Norte (Herman et al., 1992). Aunque como se comentó anteriormente es difícil separar las especies por la forma dental. Estos tiburones se distribuyen ampliamente desde las frías aguas boreales del norte hasta los trópicos, se pueden encontrar desde la zona intermareal hasta el talud continental superior (Compagno et al., 2005). En esta región del Pacifico Oriental Tropical se encuentra la especie Squatina californica (Ebert et al., 2016).

\section{Heterodontiformes Berg, 1940 \\ Heterodontidae Gray, 1851 \\ Heterodontus Blainville, 1816 \\ Heterodontus francisci Girard, 1855}

Ejemplares referidos. MHN-UABCS/SR/MICHF1 (Figura 5c); MHNUABCS/SR/MICHF2 (Figura 5d); MHN-UABCS/SR/MICHF3 (Figura 
5e); MHN-UABCS/SR/MICHF4 (Figura 5f) y MHN-UABCS/SR/ MICHF5 (Figura 5g).

Localidad y edad. Cañón El Álamo (Loc. 5), calderas El Aguajito y La Reforma, BCS, México. Formación Tirabuzón (Plioceno).

Descripción. Los ejemplares estudiados de $H$. francisci corresponden a 3 dientes anteriores y 2 posteriores, tienen las siguientes dimensiones: MHN-UABCS/SR/MICHF1 tiene de alto $1.8 \mathrm{~mm}$ y de ancho $1.7 \mathrm{~mm}$. MHN-UABCS/SR/MICHF2 tiene de alto $1.7 \mathrm{~mm}$ y de ancho $1.6 \mathrm{~mm}$. MHN-UABCS/SR/MICHF3 tiene de alto $1.8 \mathrm{~mm}$ y de ancho $2.2 \mathrm{~mm}$. MHN-UABCS/SR/MICHF4 tiene de alto $1.9 \mathrm{~mm}$ y de ancho $1.8 \mathrm{~mm}$. MHN-UABCS/SR/MICHF5 tiene de alto $14.5 \mathrm{~mm}$ y de ancho $4.6 \mathrm{~mm}$. Los dientes anteriores se caracterizan por ser más pequeños que los posteriores, conformados por una corona con tres cúspides notorias, la principal es más alta, con la raíz más baja, más estrecha que la corona. Los dientes posteriores se caracterizan por ser alargados en dirección mesial-distal con una corona que presenta una cresta transversal y el esmalte presenta plegamientos que le dan una textura rugosa que se distingue claramente en los ejemplares.

Observaciones. El género Heterodontus se caracteriza por una dentición heterodonta. Los dientes anteriores son pequeños, de hasta aproximadamente $4 \mathrm{~mm}$ de ancho, simétricos, con una corona de tres a 5 cúspides a partir de una cúspide principal más alta, la raíz es más baja y estrecha que la corona (Cappetta, 2012). Estos son tiburones de hábitos bentónicos y por lo general viven en aguas cálidastempladas y cálidas. Suelen ser de hábito bentónico y epibentónico, se encuentra en la plataforma continental del Pacífico oriental con mayor abundancia a profundidades de entre 2 a $11 \mathrm{~m}$, pero se ha observado desde la zona intermareal hasta por lo menos $150 \mathrm{~m}$ de profundidad. La especie más común en el Pacifico Oriental Tropical es Heterodontus francisci y la dentición es muy similar a los especímenes de la localidad de El Álamo (Compagno et al., 2005; Ebert et al., 2016; Herman et al., 1993).

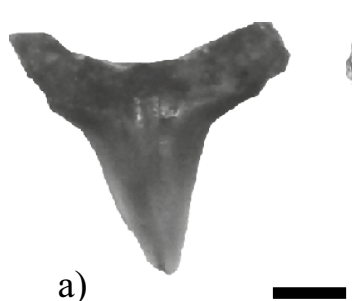

a)

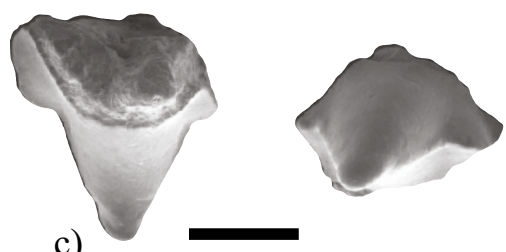

c)

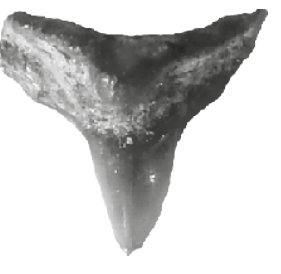

b)

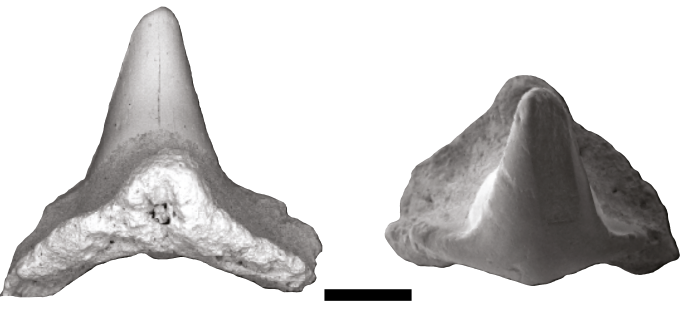

d)
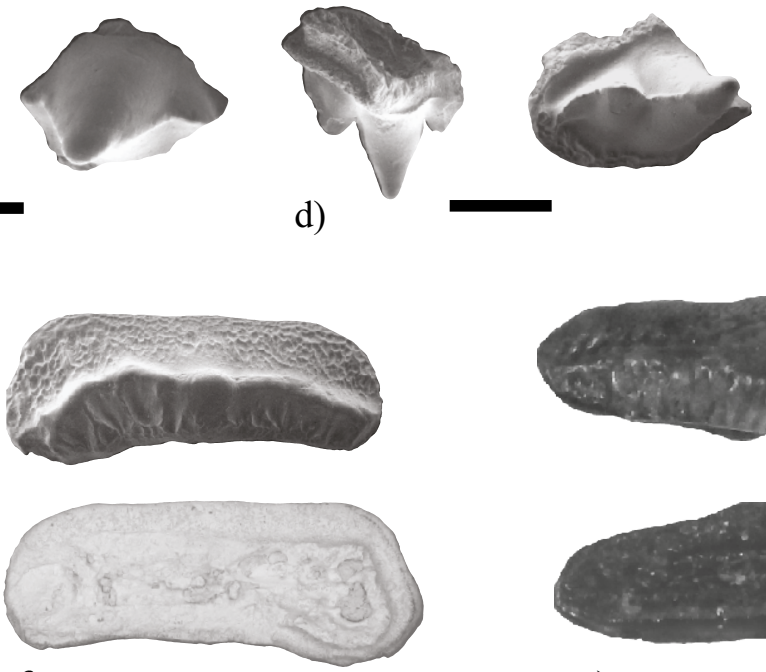

f)

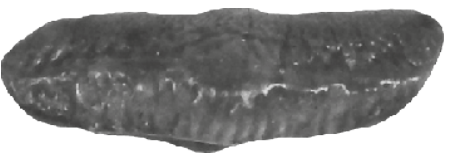

e)

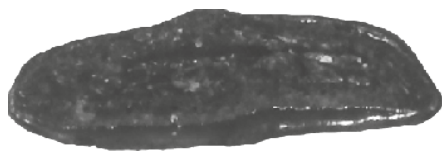

g)
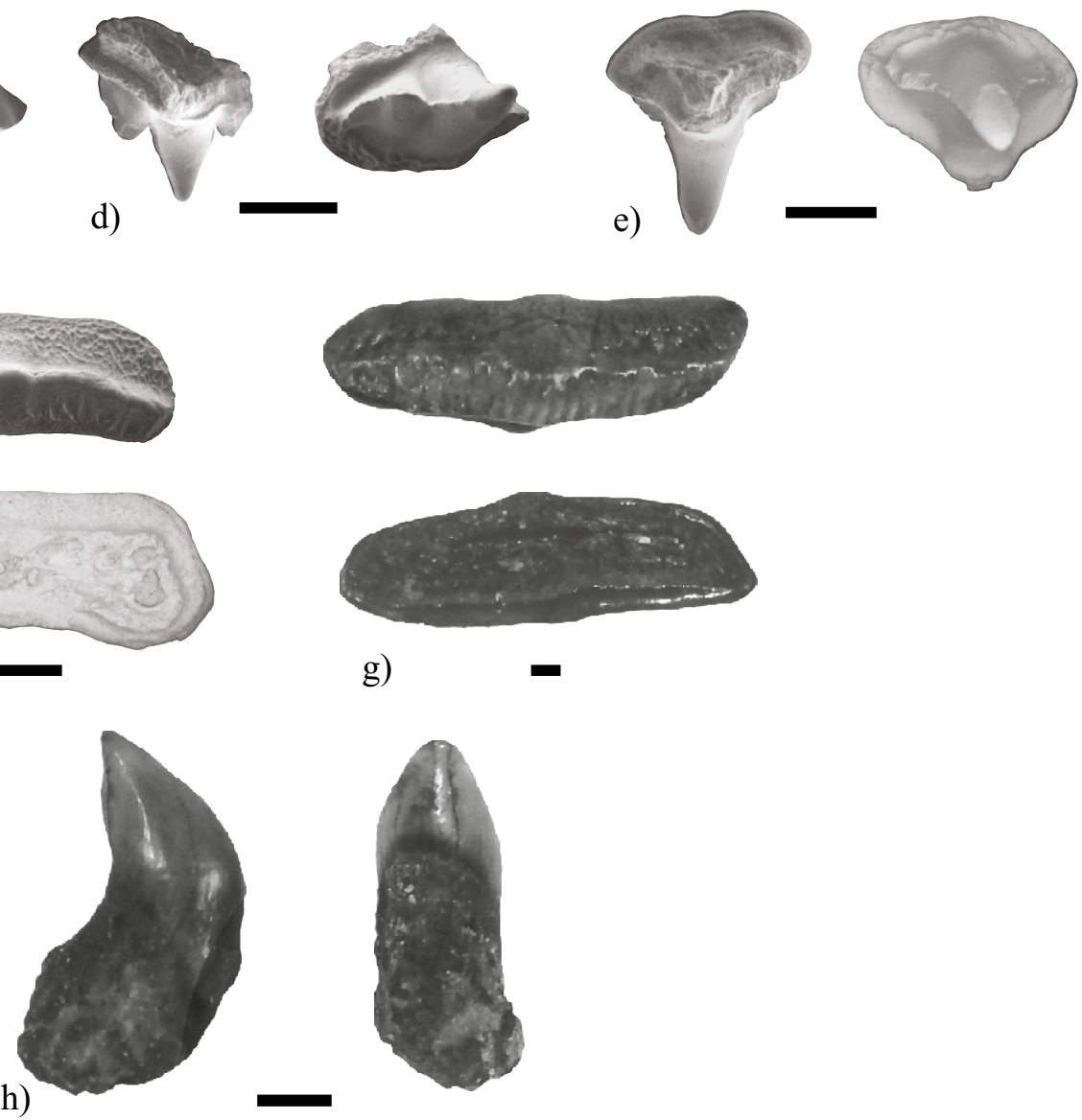

Figura 5. Tiburones Squatiniformes, Heterodontiformes y Orectolobiformes del Cañón El Álamo (Loc. 5). a-b) Squatina californica (MHN-UABCS/SR/MDS1 y MHN-UABCS/SR/MDS2). c-g) Heterodontus francisci (MHN-UABCS/SR/MICHF1, MHN-UABCS/SR/MICHF2, MHN-UABCS/SR/MICHF3, MHN-UABCS/ SR/MICHF4 y MHN-UABCS/SR/MICHF5). h) Rhincodon typus (MHN-UABCS/SR/MDRC1). Escala igual a 1mm. 
Orectolobiformes Applegate, 1972

Rhincodontidae Müller y Henle, 1839

Rhincodon Smith, 1829

Rhincodon typus Smith, 1829

Ejemplar referido. MHN-UABCS/SR/MDRC1 (Figura 5h).

Localidad y edad. Cañón El Álamo (Loc. 5), calderas El Aguajito y La Reforma, BCS, México. Formación Tirabuzón (Plioceno).

Descripción. MHN-UABCS/SR/MDRC1 es un diente inferior que tiene de alto $4.7 \mathrm{~mm}$ y de ancho $2.7 \mathrm{~mm}$. Es un diente pequeño más largo que ancho, la corona se curva hacia la cara lingual. La cara labial y lingual es muy convexa, separadas por el margen cortante afilado, sin serraciones, ni dentículos laterales, la cara lingual presenta un cinturón entre la base de la corona y la raíz. La raíz es tubular, curvándose también hacía la cara lingual.

Observaciones. Los dientes son pequeños de hasta aproximadamente $5 \mathrm{~mm}$ de alto y más largos que anchos, la cúspide perpendicular al plano basal del diente es delgada y tiene bordes de corte laterales, está ligeramente doblada lingualmente (Capetta, 2012). Las caras linguales y labiales son muy convexas. El ejemplar aquí presentado correspondería al primer registro formal de Rhincodon typus para el Plioceno de México. Este reporte se agrega a los ya conocidos del Plioceno de Costa Rica en el Alto Guayacán, Formación Uscari, de donde se ilustran varios dientes (Laurito-Mora, 1999); el de las Formaciones Pungo River del Mioceno medio de la localidad de la mina de Lee Creek en Carolina del Norte (Purdy et al., 2001). También del Mioceno medio de Francia, en la región de Montpellier (Cappetta, 1970) y en Plioceno-Pleistoceno de Japón (Kuga, 1985, en Cappetta, 2012). Actualmente, el tiburón ballena habita mares templados cálidos y tropicales, con una profundidad generalmente de 0 a $70 \mathrm{~m}$. Este tiburón prefiere aguas con temperaturas mayores a $26^{\circ} \mathrm{C}$ en el Golfo de California, estas condiciones pueden ser óptimas para la producción de plancton y organismos nectónicos (Compagno et al., 2005; Ebert et al., 2016). El género es extremadamente raro como fósil, los fósiles del Oligoceno al Plioceno son muy similares a los dientes recientes (Cappetta, 2012). La dentición de la especie actual es ilustrada en Herman et al. (1992), lo cual permite comparar las características descritas y asignar el espécimen de El Álamo a un diente inferior.

\author{
Lamniformes Berg, 1958 \\ Lamnidae Müller y Henle 1838 \\ Carcharodon Smith, 1838 \\ Carcharodon carcharias Linnaeus, 1758
}

Ejemplares referidos. MHN-UABCS/SR/CC3 (Figura 6a); MHNUABCS/SR/CC4 (Figura 6b); MHN-UABCS/SR/CC1 (Figura 6c); UABCS/SR/CC2 (Figura 6d).

Localidad y edad. Cañón El Álamo (Loc. 5), calderas El Aguajito y La Reforma, BCS, México. Formación Tirabuzón (Plioceno).

Descripción. MHN-UABCS/SR/CC3, diente superior que tiene de alto $3.5 \mathrm{~cm}$ y de ancho $3.5 \mathrm{~cm}$. MHN-UABCS/SR/CC4, diente inferior que tiene de alto $2.4 \mathrm{~cm}$ y de ancho $2.3 \mathrm{~cm}$. MHN-UABCS/SR/CC1, diente superior que tiene de alto $2.3 \mathrm{~cm}$ y ancho de $1.8 \mathrm{~cm}$. DMHN-UABCS/ SR/CC2 diente superior que tiene de alto $1.4 \mathrm{~cm}$ y de ancho de $1 \mathrm{~cm}$. Los ejemplares son de corona triangular, donde se aprecia la cara labial plana y la cara lingual ligeramente convexa. Los bordes de todos los ejemplares presentan sierras irregulares.

Observaciones. La dentición es heterodonta en la mayoría de los casos. Los lamniformes son en general pelágicos, aunque algunos géneros frecuentan aguas poco profundas cerca de la costa (Cappetta, 2012). El género Carcharodon se caracteriza por tener dientes de hasta $6 \mathrm{~cm}$ de altura, comprimidos labio-lingualmente. La corona es triangular, ancha cerca de la base, la cara labial es plana, la lingual ligeramente convexa y plana en zona media (Cappetta, 2012). Este tiburón puede habitar desde la zona costera hasta mar abierto en las plataformas continentales e insulares, en mares templados. El tiburón blanco con frecuencia se encuentra cerca de la costa hasta la zona de rompiente
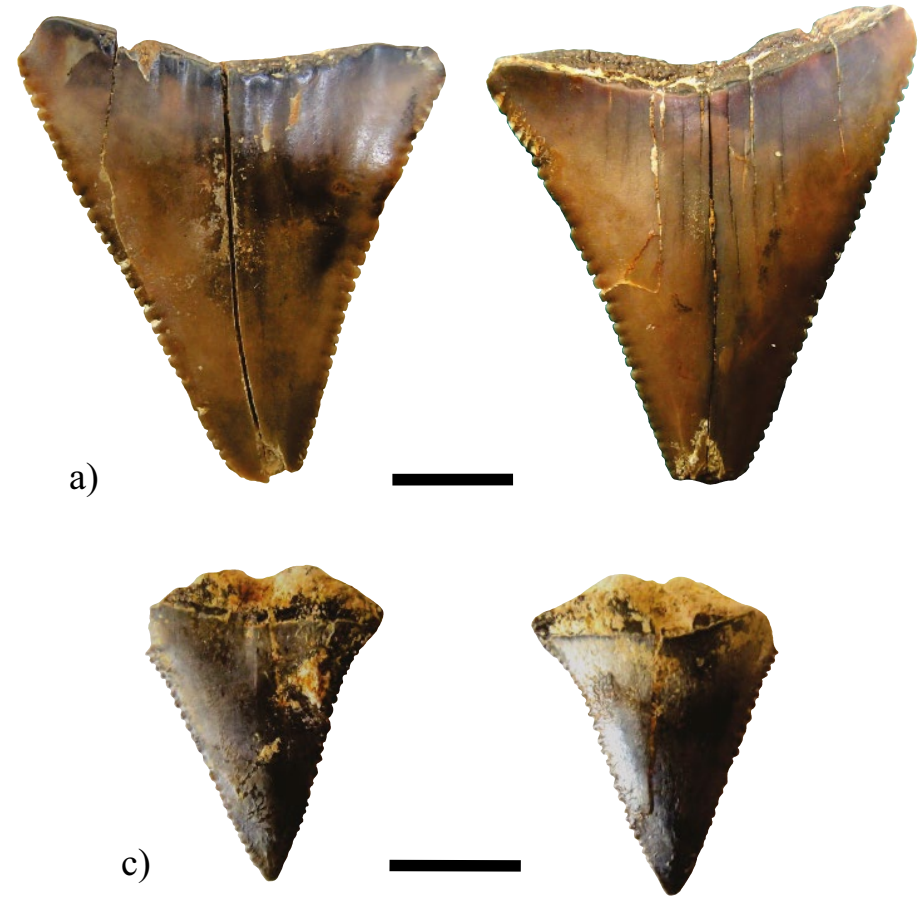

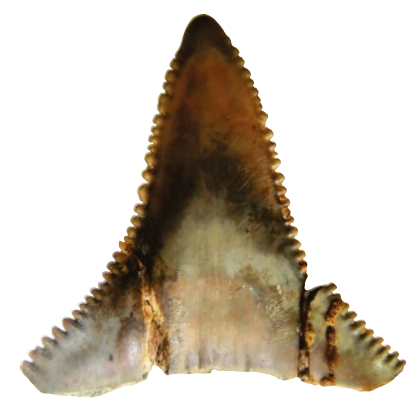

b)
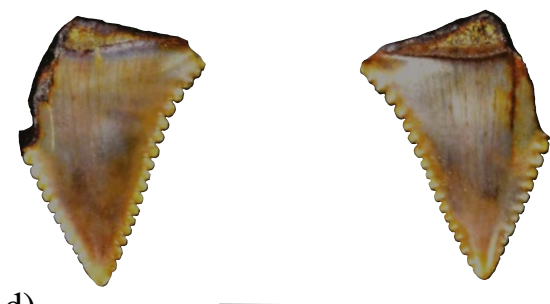

d)

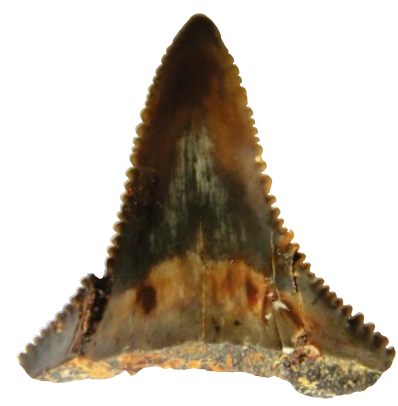

Figura 6. Lamniformes del Cañón El Álamo (Loc. 5). a-d) Carcharodon carcharias (MHN-UABCS/SR/CC3, MHN-UABCS/SR/CC4, MHN-UABCS/SR/CC1 y $\mathrm{UABCS} / \mathrm{SR} / \mathrm{CC} 2)$, todos los ejemplares se presentan en vista labial y lingual. Escala igual a $1 \mathrm{~cm}$. 
e incluso se llega a introducir en bahías poco profundas, estuarios y zonas intermareales (Compagno et al., 2005; Ebert et al., 2016).

\author{
Carcharhiniformes Compagno, 1973 \\ Triakidae Gray, 1851 \\ Triakinae Gray, 1851 \\ Triakis Müller y Henle, 1838 \\ Triakis cf. semifasciata Girard, 1855
}

Ejemplares referidos. MHN-UABCS/SR/MICCT1 (Figura 7a) y MHN-UABCS/SR/MICCT2 (Figura 7b).

Localidad y edad. Cañón El Álamo (Loc. 5), calderas El Aguajito y La Reforma, BCS, México. Formación Tirabuzón (Plioceno).

Descripción. Los dientes anteriores inferiores tienen una cúspide central, triangular, robusta y corta, inclinada hacía la comisura y una cúspide distal de pequeña altura. La cara labial presenta los pliegues verticales característicos en la base de la corona, la cual sobresale de la raíz, como delantal. La raíz esta erosionada en ambos especímenes y no es posible observar caracteres diagnósticos.

Los dientes anteriores superiores tienen una cúspide principal triangular erecta con una cúspide distal y dos cúspides mesiales. La cara labial es ligeramente convexa y tiene algunos pliegues verticales y paralelos, su base sobresale de la raíz, pero sin formar un abultamiento real. Los dientes laterales son casi simétricos con un solo par de cúspides laterales ligeramente divergentes. La raíz es bastante gruesa con una cara basal plana dividida por un surco profundo donde se abre un foramen central grande. La cúspide distal se vuelve baja y ancha en más dientes laterales.

Observaciones. El género Triakis se caracteriza por dientes pequeños que pueden ser menores de $1.5 \mathrm{~mm}$ de alto (Cappetta, 2012). En el registro fósil está restringido del Paleoceno al reciente (Cappetta, 2012). En la actualidad, la familia Triakidae es una de las familias más grandes de tiburones en términos de diversidad, con más de 40 especies vivas pertenecientes a nueve géneros. Estos tiburones se distribuyen por todo el mundo en las costas cálidas y templadas, donde son principalmente frecuentes en la plataforma continental por debajo de los $200 \mathrm{~m}$ de profundidad (Compagno et al., 2005; Ebert et al., 2016). La especie Traikis semifaciata abunda en aguas frías a templadas-cálidas en zonas costeras internas y externas, desde el estado de Washington hasta el Golfo de California, más común sobre o cerca del fondo en aguas poco profundas desde la zona intermareal hasta $4 \mathrm{~m}$ de profundidad, menos común hasta $91 \mathrm{~m}$ (Ebert et al., 2016). La morfología dental de esta especie es ilustrada por Herman et al. (1988).

\section{Galeorhininae Gill, 1862 \\ Galeorhinus Blainville 1816 \\ Galeorhinus galeus (Linnaeus, 1758)}

Ejemplares referidos. MHN-UABCS/SR/MICCG1 (Figura 7c) y MHN-UABCS/SR/MICCG2 (Figura 7d).

Localidad y edad. Cañón El Álamo (Loc. 5), calderas El Aguajito y La Reforma, BCS, México. Formación Tirabuzón (Plioceno).

Descripción. MHN-UABCS/SR/MICCG1 corresponde a un inferior lateral de alto $2.5 \mathrm{~mm}$ y ancho $3.8 \mathrm{~mm}$ y $\mathrm{MHN}-\mathrm{UABCS} / \mathrm{SR} / \mathrm{MICCG} 2$ es un diente inferior lateral de alto $2.2 \mathrm{~mm}$ y ancho de $4.0 \mathrm{~mm}$. Los ejemplares se caracterizan por una corona ancha con una cúspide triangular inclinada hacia la comisura, el lado distal se caracteriza en estos dientes por tener muy pobremente desarrollados los dentículos laterales, que son diagnósticos en los dientes superiores. La raíz es delgada y muestra una cara basal ancha, con un canal nutritivo amplio. Observaciones. El género tiene una distribución temporal del Cretácico al reciente (Cappetta, 2012). Estos tiburones tienen una distribución casi cosmopolita, habitan aguas templadas continentales e insulares, que van desde bahías hasta mar abierto, con un rango de profundidad que oscila entre 2 a $471 \mathrm{~m}$ (Ebert et al., 2016). La morfología dental es ilustrada por Herman et al. (1988).

Triakinae Gray, 1851

Mustelus Linck, 1790

Mustelus sp.

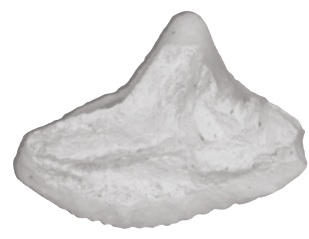

a)

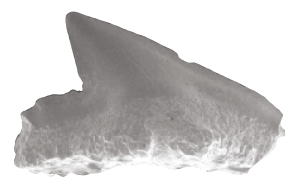

c)
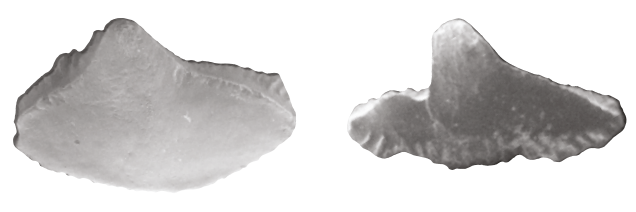

b)

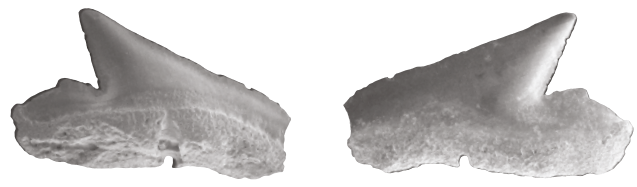

d)
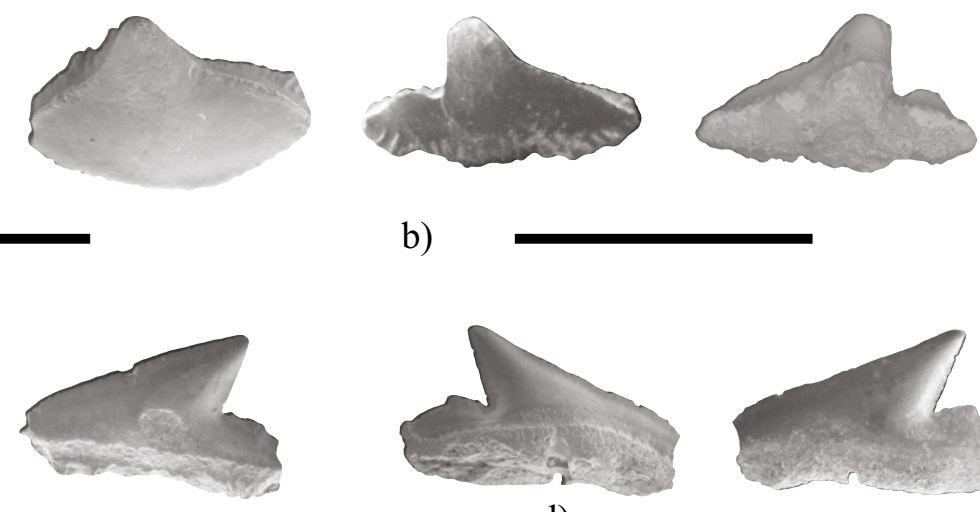

$+$
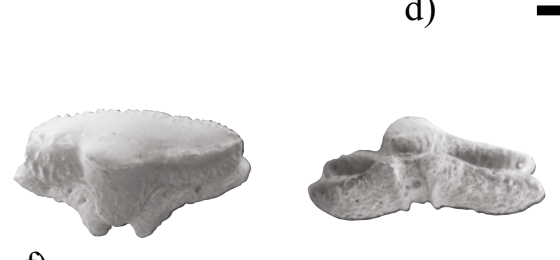

f)

g)
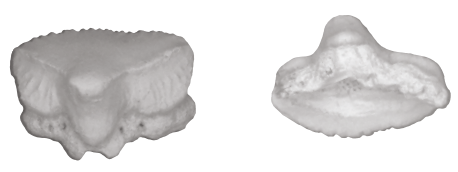

e)

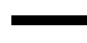

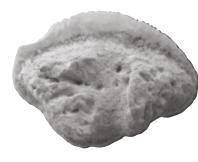

Figura 7. Carcharhiniformes del Cañón El Álamo (Loc. 5). a-b) Triakis cf. Semifasciata (MHN-UABCS/SR/MICCT1 y MHN-UABCS/SR/MICCT2). c-d) Galeorhinus sp. (MHN-UABCS/SR/MICCG1 y MHN-UABCS/SR/MICCG2). e-g) Mustelus sp. (MHN-UABCS/SR/MICCML, MHN-UABCS/SR/MICCMC y MHN-UABCS/ $\mathrm{SR} / \mathrm{MICMH})$. 
Ejemplares referidos. MHN-UABCS/SR/MICCML (Figura 7e), MHN-UABCS/SR/MICCMC (Figura 7f) y MHN-UABCS/SR/MICMH (Figura 7g).

Localidad y edad. Cañón El Álamo (Loc. 5), calderas El Aguajito y La Reforma, BCS, México. Formación Tirabuzón (Plioceno).

Descripción. Los dientes corresponden al tipo triturador. La corona tiene una cresta transversal, cuspidada en el centro, el borde labial presenta el contorno convexo sobrepasa la raíz, y tiene los pliegues verticales. La cara lingual presenta pliegues y verticales en el esmalte, la úvula central larga. Los dientes mostrados corresponden a un anterior, posterior y lateral, apreciándose como se alargan de acuerdo a su posición en la mandíbula.

Observaciones. El género Mustelus se caracteriza por una dentición de tipo triturador, los dientes son parecidos a los de rhinobatoideos (Cappetta, 2012). Estos tiburones son pequeños por lo general de un metro de largo, suelen habitar la plataforma continental e insular en aguas frías templadas a aguas tropicales (Ebert et al., 2016). Los dientes de El Álamo se pueden asociar a la morfología de Mustelus californicus Gill, 1864, ilustrados en Castro (2011).

\section{Carcharhinidae Jordan y Evermann, 1896 Galeocerdo Müller y Henle, 1837 \\ Galeocerdo cuvier Péron y Lesueur, 1822}

Ejemplares referidos. MHN-UABCS/SR/GC1 (Figura 8a).

Localidad y edad. Cañón El Álamo (Loc. 5), calderas El Aguajito y La Reforma, BCS, México. Formación Tirabuzón (Plioceno).

Descripción. MHN-UABCS/SR/GC1 es un diente superior que tiene de alto $1.4 \mathrm{~cm}$ y ancho de $0.85 \mathrm{~cm}$. El diente muestra una corona de forma triangular, ancha y alta con una cúspide curvada hacia la comisura. La cara labial de la corona es más plana y sobresale hacia la raíz por un abultamiento, la cara lingual es más convexa. El ejemplar está roto, no presenta el lóbulo distal.

Observaciones. G. cuvier es un tiburón circumglobal, en mares templados y tropicales, tiene hábitos costeros, con una amplia adaptación en diferentes hábitats marinos, o adyacentes a las plataformas continentales e insulares a profundidades desde la superficie e intermareales hasta $140 \mathrm{~m}$. Este tiburón prefiere las áreas turbias en aguas continentales, islas grandes o islas volcánicas, donde las corrientes fluviales pueden contribuir a la existencia de una alta densidad de organismos presas, puede encontrarse en estuarios, atolones y lagunas (Compagno, 1984b).

Carcharhinidae Jordan y Evermann, 1896 Rhizoprionodon Whitley, 1929

Rhizoprionodon longurio Jordan y Gilbert, 1882

Ejemplares referidos. MHN-UABCS/SR/R2 (Figura 8b); MHNUABCS/SR/MRP4 (Figura 8c); MHN-UABCS/SR/R1 (Figura 8d).

Localidad y edad. Cañón El Álamo (Loc. 5), calderas El Aguajito y La Reforma, BCS, México. Formación Tirabuzón (Plioceno).

Descripción. MHN-UABCS/SR/R2 es un diente superior que tiene de alto $0.75 \mathrm{~cm}$ y ancho de $0.95 \mathrm{~cm}$. MHN-UABCS/SR/MRP4 es un diente inferior que tiene de alto $0.9 \mathrm{~cm}$ y ancho de $0.8 \mathrm{~cm}$. MHN-UABCS/ $\mathrm{SR} / \mathrm{R} 1$ es también un diente inferior que tiene de alto $1 \mathrm{~cm}$ y ancho de $1.25 \mathrm{~cm}$. Los dientes mostrados corresponden a posiciones superior $\mathrm{e}$ inferiores, tienen una corana casi vertical, los dientes superiores tienen la cúspide curvada hacía la comisura. Los dientes presentan serraciones poco desarrolladas en el lóbulo distal. La cúspide está inclinada fuertemente hacia la comisura; la base de la corona está bastante extendida con talones distales altos, redondeados y levemente aserrados; en las caras labiales la raíz es baja y el borde basal es rectilíneo.

Observaciones. Estos tiburones suelen habitar mares tropicales en las plataformas continentales internas, en profundidades que pueden oscilar entre intermareales hasta al menos $27 \mathrm{~m}$ (Compagno, 1984b). Esta especie está restringida al Pacifico Oriental Tropical (Compagno et al. 2005, Ebert et al. 2016). Carrillo-Briceño et al. (2014) reportan la especie fósil con un rango de edad del Mioceno medio-tardío al Pleistoceno en Ecuador.

\section{Carcharhinidae Jordan y Evermann, 1896 Carcharhinus Blainville, 1816 Carcharhinus albimarginatus Rüppell, 1837}

Ejemplar referido. MHN-UABCS/SR/GC1 (Figura 9a). Localidad y edad. Cañón El Álamo (Loc. 5), calderas El Aguajito y La Reforma, BCS, México. Formación Tirabuzón (Plioceno).

Descripción. MHN-UABCS/SR/GC1 es un diente superior que tiene de alto $1.25 \mathrm{~cm}$ y ancho de $0.75 \mathrm{~cm}$. El ejemplar muestra una cara labial plana y la cara lingual es ligeramente convexa. La corona tiene una forma triangular ancha aplanada labio-lingualmente y la cúspide está poco curvada hacía la comisura. Los lóbulos laterales se fracturaron y no están presentes.

Observaciones. El género Carcharhinus cuenta con más de 30 especies recientes, presentan una morfología dental bastante variada, desde especies con dientes superiores de cúspides angostas hasta especies con dientes superiores con gruesas cúspides (Capetta, 2012). C. albimarginatus es un tiburón que habita zonas costeras y pelágicas tropicales, por lo general en plataformas insulares, pero también se puede encontrar en mar abierto, en profundidades que oscilan desde la zona intermareal hasta 600 a $800 \mathrm{~m}$. Este tiburón tiene una fuerte preferencia por islas, arrecifes y bancos coralinos; puede encontrarse desde el interior de las lagunas costeras y cerca de la desembocadura de los ríos hasta fuera de la zona costera, pero no se considera como un tiburón oceánico (Compagno, 1984b; Compagno et al. 2005; Ebert et al. 2016).

\section{Carcharhinus brachyurus Günther, 1870}

Ejemplares referidos. MHN-UABCS/SR/CBY4 (Figura 9b); MHNUABCS/SR/CBY8 (Figura 9c).

Localidad y edad. Cañón El Álamo (Loc. 5), calderas El Aguajito y La Reforma, BCS, México. Formación Tirabuzón (Plioceno).

Descripción. MHN-UABCS/SR/CBY4 es un diente superior que tiene de alto $0.7 \mathrm{~cm}$ y ancho de $0.7 \mathrm{~cm}$. MHN-UABCS/SR/CBY8 es un diente inferior que tiene de alto $0.6 \mathrm{~cm}$ y ancho de $0.6 \mathrm{~cm}$. Los dientes superiores se caracterizan por tener cúspides estrechas e inclinadas distalmente. Los dientes inferiores muestran una cúspide esbelta y vertical en la base, el ápice de la cúspide se curva hacia la comisura. Observaciones. Presenta un rango estratigráfico del Mioceno al reciente en muchas localidades de Norteamérica y Europa (Marsili, 2007). La distribución de restos fósiles de C. brachyurus, de edad Mioceno medio a Plioceno, a lo largo de la costa occidental de América del Sur se extiende desde Chile central hasta el norte de Ecuador (CarrilloBriceño et al., 2013; Carrillo-Briceño et al., 2014). En la cuenca del este de Pisco, C. brachyurus se ha registrado en las proximidades de Ocucaje tanto en los estratos del Mioceno inferior de la Formación Chilcatay expuestos en el Cerro Sichuita como en la porción del Mioceno superior de la Formación Pisco en Cerro Colorado (Alván de la Cruz, 2008). Esta especie de tiburón también ha sido reportada por González-Barba y Martínez (2010) en el norte de Perú en la Formación Miramar de Quebrada Pajaritos (Mioceno) y Chusis (Plioceno). Reportado para el Mioceno-Plioceno de Baja California (González Barba y Thies, 2000). La especie reciente tiene una distribución en las zonas neríticas y tropicales, y se le conoce como cobrizo por su color (Compagno et al., 2005; Ebert et al., 2016). 

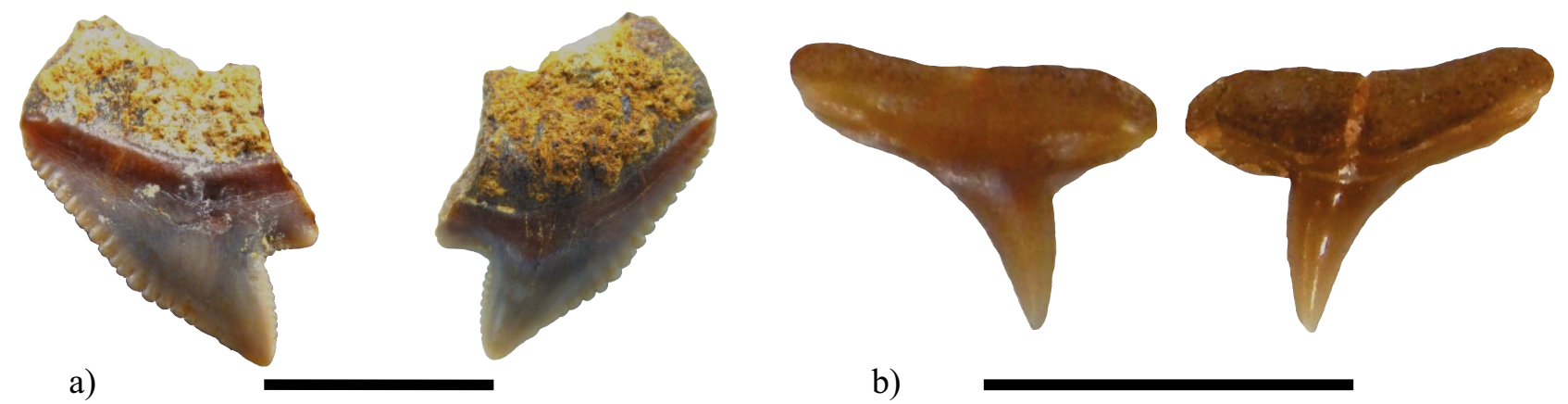

b)
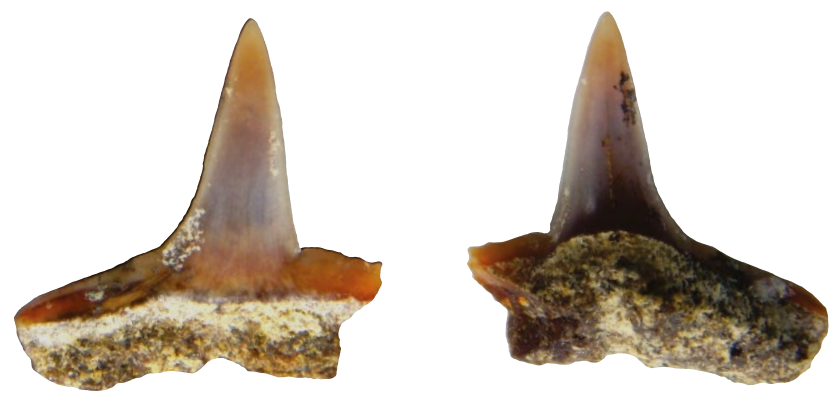

c)
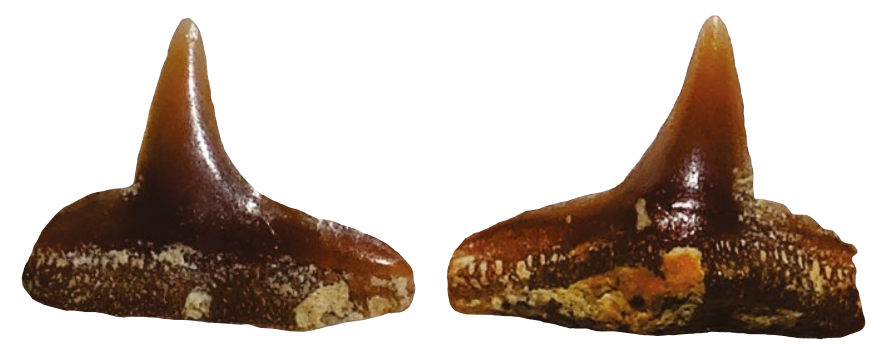

d)

Figura 8. Carchahiniformes del Cañón El Álamo (Loc. 5). a) Galeocerdo cuvier (MHN-UABCS/SR/GC1), diente superior en vista labial y ligual. b-d) Rhizoprionodon longurio (MHN-UABCS/SR/R2 diente superior; MHN-UABCS/SR/MRP4 diente inferior; MHN-UABCS/SR/R1 diente inferior), todos los ejemplares se presentan en vista labial y lingual. Escala igual a $1 \mathrm{~cm}$.
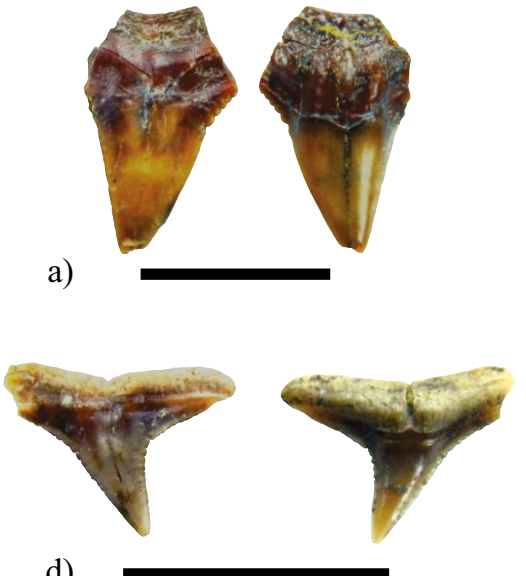

d)

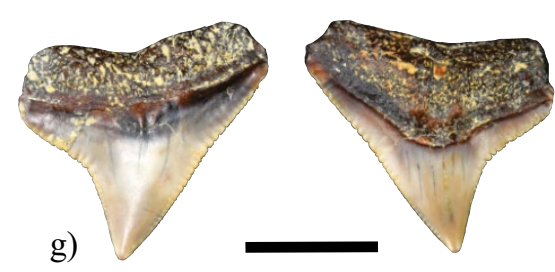

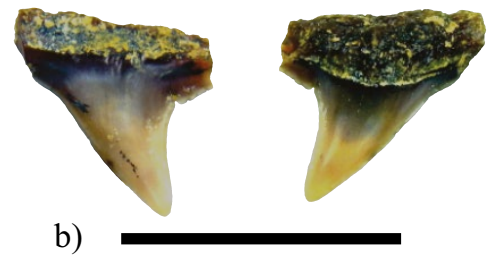

b)

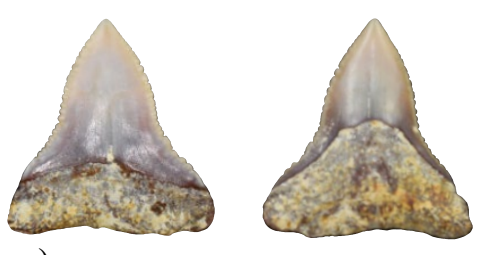

e)

h)

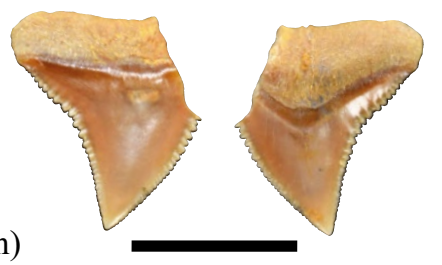

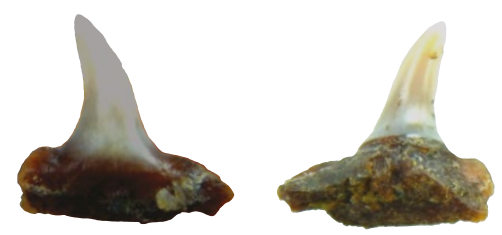

c)
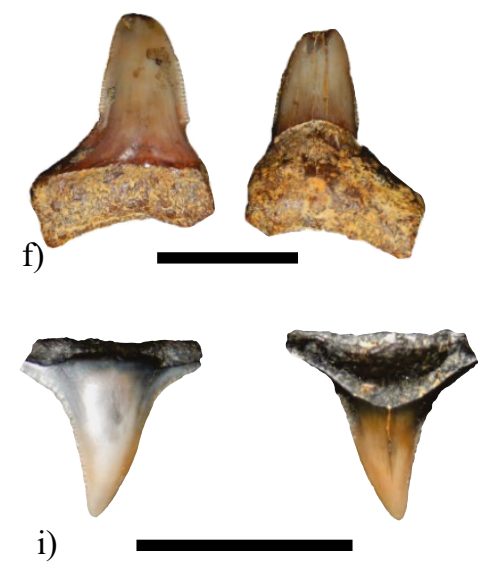

Figura 9. Carcharhinus del Cañón El Álamo (Loc. 5). Los ejemplares se muestran en vistas labiales y linguales. a) Carcharhinus. albimarginatus (MHN-UABCS/SR/ GC1). b-c) Carcharhinus brachyurus (MHN-UABCS/SR/CBY4 y MHN-UABCS/SR/CBY8). d) Carcharhinus brevipinna (MHN-UABCS/SR/CB7). e) Carcharhinus leucas (MHN-UABCS/SR/CO2). f) Carcharhinus longimanus (MHN-UABCS/SR/CLM1). g-h) Carcharhinus obscurus (MHN-UABCS/SR/CO5 y MHN-UABCS/ $\mathrm{SR} / \mathrm{CO} 3$ ). i) Carcharhinus limbatus (MHN-UABCS/SR/CLB1). Escala igual a $1 \mathrm{~cm}$. 


\section{Carcharhinus brevipinna Müller y Henle, 1839}

Ejemplar referido. MHN-UABCS/SR/CB7 (Figura 9d).

Localidad y edad. Cañón El Álamo (Loc. 5), calderas El Aguajito y La Reforma, BCS, México. Formación Tirabuzón (Plioceno).

Descripción. MHN-UABCS/SR/CB7 es un diente superior que tiene de alto $0.6 \mathrm{~cm}$ y ancho de $0.85 \mathrm{~cm}$. El diente corresponde a una posición superior, lateral, izquierda. La corona es triangular, esbelta y alargada. Los lóbulos de la corona se extienden sobre la raíz alargada. Los bordes cortantes de la corona presentan las serraciones regulares, poco desarrolladas.

Observaciones. C. brevipinna es un tiburón casi cosmopolita, aunque ahora ausente en la costa americana del Pacífico, con distribución costa-pelágico de aguas templadas cálidas y tropicales, encontrándose en ambientes de plataforma continental e insular, comúnmente se halla en aguas someras a una profundidad inferior a $30 \mathrm{~m}$, pero puede encontrarse a profundidades de hasta $75 \mathrm{~m}$ (Compagno, 1984b; Compagno et al., 2005; Ebert et al., 2016). Esta especie no había sido reportada para el Plioceno en Norteamérica.

\section{Carcharhinus leucas Müller y Henle, 1839}

Ejemplar referido. $\mathrm{MHN}-\mathrm{UABCS} / \mathrm{SR} / \mathrm{CO} 2$ (Figura 9e). Localidad y edad. Cañón El Álamo (Loc. 5), calderas El Aguajito y La Reforma, BCS, México. Formación Tirabuzón (Plioceno).

Descripción. MHN-UABCS/SR/CO2 es un diente superior y tiene de alto $1.05 \mathrm{~cm}$ y ancho de $1 \mathrm{~cm}$. Puede corresponder al primer anterior por la simetría triangular que presenta. La corona tiene una cúspide triangular, ancha, con los bordes cortantes serrados característicos en esta especie, más gruesos en la base de la corona, que en la cúspide. La raíz es gruesa con la base muy horizontal, presentando el canal nutritivo en la cara lingual.

Observaciones. C. leucas tiene un amplio registro fósil a partir del Mioceno en América, Europa, África, Asia (Purdy et al., 2001, Marsili, 2007; Landini et al., 2019). Es un tiburón tropical y cosmopolita, que habita zonas costeras, estuarios, riberas y lagunas, generalmente se encuentra en aguas someras de menos de $30 \mathrm{~m}$ de profundidad, pero el rango de profundidad a la cual habita oscila entre 1 a $152 \mathrm{~m}$; puede encontrarse en lagunas costeras hiposalinas e hipersalinas y en las desembocaduras de ríos (Compagno et al., 2005; Ebert et al., 2016). Con respecto al registro fósil en la costa del Pacífico de América del Sur, $C$. leucas solo se ha registrado en Perú, tanto de la Formación Miramar como de la Formación Pisco (González-Barba y Martínez, 2010). Ha sido reportado en depósitos del Mioceno-Plioceno de Baja California (González Barba y Thies, 2000).

\section{Carcharhinus longimanus Poey, 1861}

Ejemplar referido. MHN-UABCS/SR/CLM1 (Figura 9f). Localidad y edad. Cañón El Álamo (Loc. 5), calderas El Aguajito y La Reforma, BCS, México. Formación Tirabuzón (Plioceno).

Descripción. MHN-UABCS/SR/CLM1 es un diente inferior anterolateral que tiene de alto $1.5 \mathrm{~cm}$ y ancho de $1.3 \mathrm{~cm}$. La raíz de este diente está incompleta. La corona es triangular, alta, vertical, reduciendo en grosor hacia el ápice. La raíz es alta y robusta.

Observaciones. C. longimanus tiene un registro fósil en el Plioceno de Europa y Norteamerica (Marsili, 2007). Es un tiburón oceánicoepipelágico, ocasionalmente costero, de aguas tropicales-templadas a cálidas, generalmente en mar abierto. Sin embargo, se ha encontrado en aguas poco profundas (alrededor de los $35 \mathrm{~m}$ ), particularmente en islas oceánicas o en áreas continentales donde la plataforma es muy estrecha pero generalmente se encuentra en aguas por debajo de los
$184 \mathrm{~m}$ de profundidad. Se encuentra en aguas con temperaturas que oscilan entre $18^{\circ} \mathrm{C}$ y $28^{\circ} \mathrm{C}$ (Compagno, 1984b; Compagno et al., 2005; Ebert et al., 2016).

\section{Carcharhinus obscurus Lesueur, 1818}

Ejemplares referidos. MHN-UABCS/SR/CO5 (Figura 9g); MHNUABCS/SR/CO3 (Figura 7h).

Localidad y edad. Cañón El Álamo (Loc. 5), calderas El Aguajito y La Reforma, BCS, México. Formación Tirabuzón (Plioceno).

Descripción. MHN-UABCS/SR/CO5 es un diente superior que tiene de alto $1.55 \mathrm{~cm}$ y ancho de $1.8 \mathrm{~cm}$. MHN-UABCS/SR/CO3 también es un diente superior que tiene de alto $1.25 \mathrm{~cm}$ y ancho de $0.9 \mathrm{~cm}$, la raíz de este diente está rota. La forma del diente es triangular con sierras en los bordes laterales. La cara labial es plana mientras que la lingual es convexa con una evidente división entre la base de la corona y la raíz. La raíz es alta y se caracteriza por tener un surco axial en la zona lingual poco desarrollado. El margen basal de la raíz es arqueado.

Observaciones. C. obscurus ha sido reportado en depósitos del Mioceno en Venezuela (Sánchez-Villagra et al., 2000; Carrillo-Briceño et al., 2015), Panamá (Carrillo-Briceño et al., 2015) y América del Norte (Applegate, 1986; González Barba y Thies, 2000); en localidades del Plioceno de Carolina del Norte (Purdy et al., 2001) y California (Applegate, 1978) y el Plioceno de Florida (Scudder et al., 1995) y en Italia (Cigala Fulgosi, 1986; Marsili, 2007). C. obscurus es un tiburón costero- pelágico, de aguas templadas y tropicales, habita desde plataforma continental e insular hasta aguas oceánicas, que abarca desde la zona de oleaje hasta profundidades de $400 \mathrm{~m}$. Suele preferir zonas con baja salinidad (Compagno, 1984b; Compagno et al, 2005; Ebert et al., 2016).

\section{Carcharhinus limbatus Müller y Henle, 1839}

Ejemplares referidos. MHN-UABCS/SR/CLB1 (Figura 9i). Localidad y edad. Cañón El Álamo (Loc. 5), calderas El Aguajito y La Reforma, BCS, México. Formación Tirabuzón (Plioceno).

Descripción. MHN-UABCS/SR/CLB1 es un diente superior que tiene de alto $0.8 \mathrm{~cm}$ y ancho de $0.9 \mathrm{~cm}$. El diente tiene incompleta la raíz. La corona es larga y angosta, con sierras en los márgenes cortantes, la curvatura hacia la comisura es poco notable, comparado con otras especies del género.

Observaciones. Tiene un registro del Mioceno medio al Plioceno en la península de Baja California (González Barba y Thies, 2000). C. limbatus es un tiburón pelágico de aguas tropicales y templadas, habita las zonas adyacentes a las plataformas continentales e insulares. Se puede encontrar cerca de la línea la costa, fuera de desembocaduras de ríos y estuarios, en lagunas costeras poco profundas, y las zonas con mayor salinidad de los manglares, no se introduce mucho en el agua dulce (Compagno, 1984b, Compagno et al., 2005; Ebert et al., 2016).

Negaprion Whitley, 1940

Negaprion brevirostris Poey, 1868

Ejemplares referidos. MHN-UABCS/SR/NB5 (Figura 10a), diente superior. MHN-UABCS/SR/NB7 (Figura 10b), diente inferior.

Localidad y edad. Cañón El Álamo (Loc. 5), calderas El Aguajito y La Reforma, BCS, México. Formación Tirabuzón (Plioceno).

Descripción. MHN-UABCS/SR/NB5, es un diente superior que tiene de alto $1.25 \mathrm{~cm}$ y ancho de $0.8 \mathrm{~cm}$, la raíz está incompleta. La corona angosta y alargada, presenta curvamiento hacía la comisura. MHN$\mathrm{UABCS} / \mathrm{SR} / \mathrm{NB} 7$, es un diente inferior que tiene de alto $1.3 \mathrm{~cm}$ y ancho 

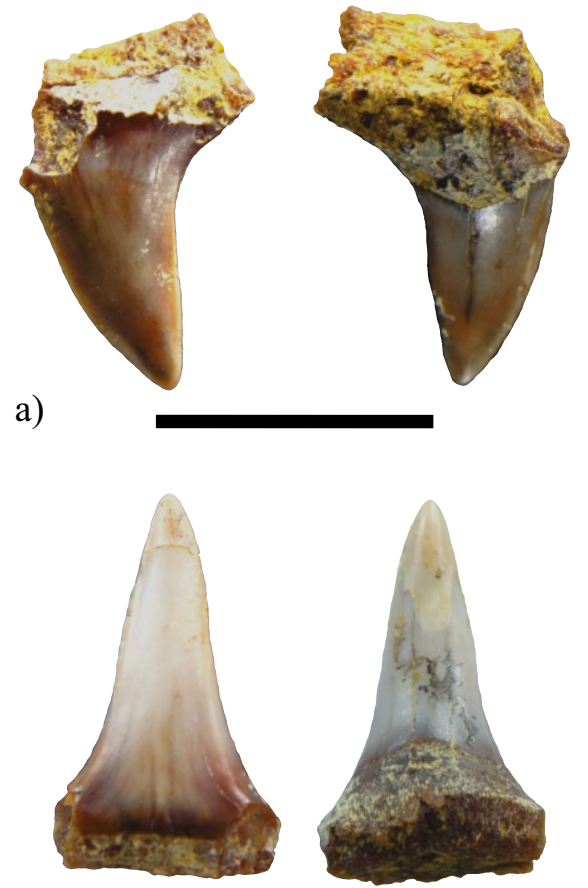

b)

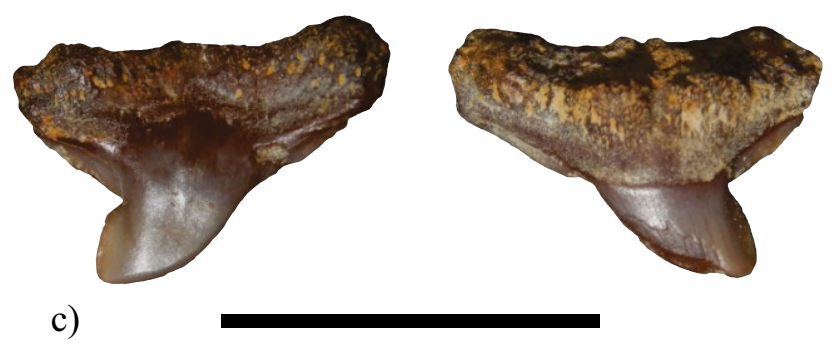

Figura 10. Dientes fósiles de los géneros Negaprion y Sphyrna. a-b) Negaprion brevirostris (MHN-UABCS/SR/NB5 diente superior y MHN-UABCS/SR/NB7 diente inferior). c) Sphyrna zygaena (MHN-UABCS/SR/SZ4). Todos los ejemplares se presentan en vista labial y lingual. Escala igual a $1 \mathrm{~cm}$.

de $0.75 \mathrm{~cm}$, también este diente tiene la raíz incompleta. La corona es angosta y alargada, en forma vertical.

Observaciones. Tiene un registro del Mioceno medio al Plioceno en la península de Baja California (González Barba y Thies, 2000). N. brevirostris en un tiburón que se caracteriza por ser generalmente costero de aguas tropicales. Se puede encontrar en un ambiente de plataforma continental e insular desde la zona intermareal hasta por lo menos 92 $\mathrm{m}$ de profundidad. Ocurre comúnmente alrededor de los arrecifes de coral, manglares, en fondos de areno-fangosos, en la desembocadura de ríos con alta salinidad, lagunas o en bahías (Compagno, 1984b, Compagno et al. 2005; Ebert et al., 2016).

Sphyrnidae Gill, 1872

Sphyrna Rafinesque, 1810

Sphyrna zygaena Linnaeus, 1758

Ejemplar referido. MHN-UABCS/SR/SZ4 (Figura 10c).

Localidad y edad. Cañón El Álamo (Loc. 5), calderas El Aguajito y La Reforma, BCS, México. Formación Tirabuzón (Plioceno).

Descripción. MHN-UABCS/SR/SZ4 es un diente superior que tiene de alto $0.6 \mathrm{~cm}$ y ancho de $1 \mathrm{~cm}$, tiene la raíz incompleta. El ejemplar se caracteriza por estar labio-lingualmente aplanado, tienen una cúspide triangular, no muy ancha, que está doblada hacia la comisura.

Observaciones. Los representantes de esta familia se caracterizan por un cráneo con expansiones laterales desarrolladas en cuyo extremo se localizan los ojos y las fosas nasales. El desarrollo de estas expansiones varía de una especie a otra. Estos tiburones habitan aguas templadas y cálidas cerca y fuera de la costa (Cappetta, 2012). S. zygaena es un tiburón martillo costero-pelágico y semi-oceánico que se encuentra cerca de la costa y en aguas poco profundas sobre la plataforma continental e insular hasta muy próximo a la costa. Se puede encontrar en aguas someras como la zona intermareal o zona de rompiente hasta profundidades mayores a 20 metros (Compagno, 1984b, Compagno et al., 2005; Ebert et al., 2016). La especie ha sido reportada para el Mioceno-Plioceno de la península de Baja California (González barba y Thies, 2000).

$$
\begin{gathered}
\text { Superorden Batomorphii Cappetta, } 1980 \\
\text { Rajiformes Berg, } 1940 \\
\text { Rhinobatidae Müller y Henle, } 1837 \\
\text { Rhinobatos Linck, } 1790 \\
\text { Rhinobatos sp. }
\end{gathered}
$$

Ejemplar referido. MHN-UABCS/SR/MICRB (Figura 11a). Localidad y edad. Cañón El Álamo (Loc. 5), calderas El Aguajito y La Reforma, BCS, México. Formación Tirabuzón (Plioceno).

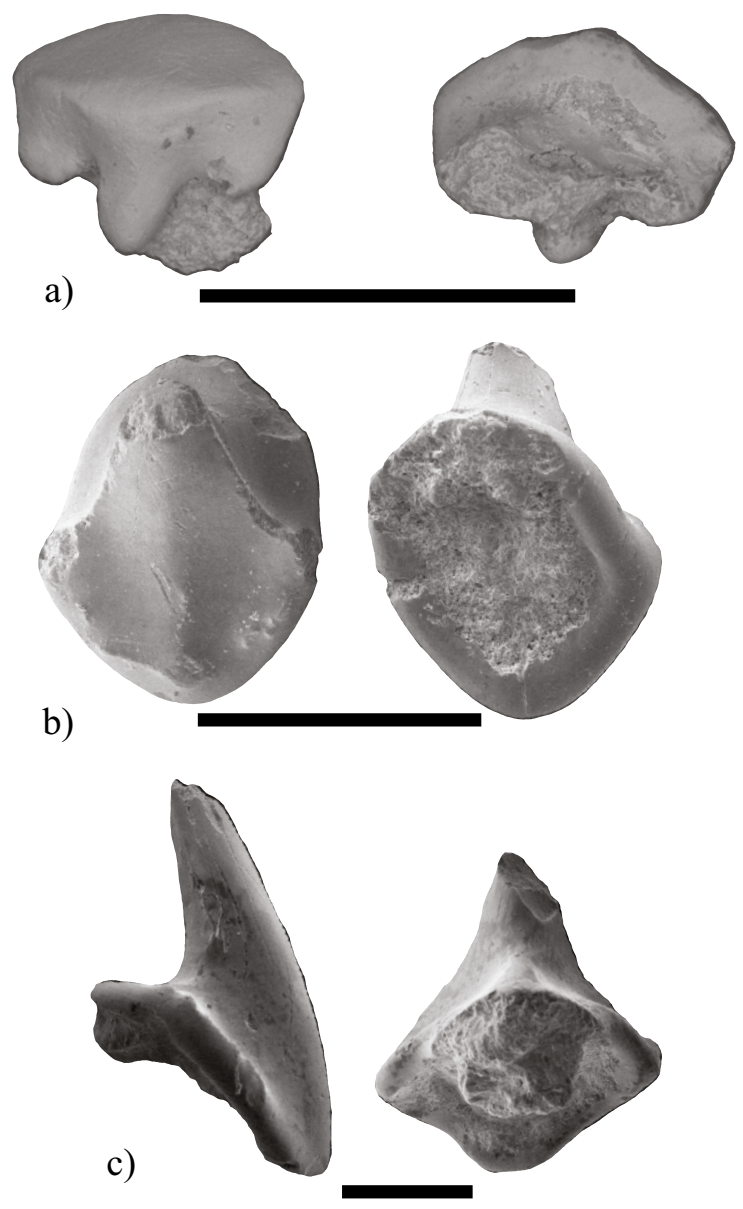

Figura 11. Dientes fósiles de las familias Rhinobatidae y Rajidae. a) Rhinobatos sp. (MHN UABCS/SR/MICRB). b-c) Raja sp. (MHN-UABCS/SR/MICRD1 y MHN-UABCS/SR/MICRD2). Escala igual a $1 \mathrm{~mm}$. 
Descripción. MHN-UABCS/SR/MICRB es un diente aislado del género Rhinobatos. El diente presenta una corona alta, masiva, con una cresta intermedia entre las partes labial y lingual, en vista apical la parte anterior de la corona desciende sobrepasando la raíz, con un contorno convexo, mientras que la parte posterior presenta tres lóbulos (úvulas), con el intermedio más largo. Solo un lóbulo de la raíz esta preservado. Observaciones. En la península de Baja California el género cuenta con un registro que abarca del Eoceno al Plioceno (González Barba y Thies, 2000). Estos batoideos son de hábitos bentónicos frecuentan las aguas típicamente cálidas de plataforma continental, pero pueden vivir a una profundidad de más de 200 m (Nair y Lal Mohan 1973, en Cappetta, 2012). La familia incluye actualmente alrededor de 40 especies. Los dientes son pequeños y, en consecuencia, rara vez colectados. Sin embargo, debe notarse que son comunes en muchas localidades fosilíferas (Cappetta, 2012).

\section{Rajidae Blainville, 1816 Raja Linnaeus, 1758 Raja sp.}

Ejemplares referidos. MHN-UABCS/SR/MICRD1 (Figura 11b) y MHN-UABCS/SR/MICRD2 (Figura 11c).

Localidad y edad. Cañón El Álamo (Loc. 5), calderas El Aguajito y La Reforma, BCS, México. Formación Tirabuzón (Plioceno).

Descripción. MHN-UABCS/SR/MICRD1 y MHN-UABCS/SR/ MICRD2 son dos dientes que durante la revisión han sido asignados a Raja sp. Los dientes son cuspados, característicos de machos, con la base y la cúspide de la corona, volcándose hacia atrás, en ambos especímenes no se conservó la raíz.

Observaciones. En la península de Baja California el género cuenta con un registro que abarca del Eoceno al Plioceno (González Barba y Thies, 2000). La dentición del género se compone de muchas filas de dientes estrechamente imbricadas, y un dimorfismo sexual en la morfología de los dientes, que siempre tienen esmalte liso (Cappetta, 2012). En estos batoides la cola no es muy robusta. Hay dos pequeñas aletas dorsales cerca de del extremo de la cola. La aleta caudal es pequeña o está ausente. Las aletas pélvicas tienen muescas (Cappetta, 2012).

\section{Myliobatiformes Compagno, 1973 Dasyatidae Jordan, 1888 \\ Dasyatis Rafinesque, 1810 \\ Dasyatis sp.}

Ejemplares referidos. MHN-UABCS/SR/MICMD1 (Figura 12a), MHN-UABCS/SR/MICMD2 (Figura 12b), MHN-UABCS/ SR/MICMD3 (Figura 12c), MHN-UABCS/SR/MICMD4 (Figura 12d), MHN-UABCS/SR/MICMD5 (Figura 12e), MHN-UABCS/ SR/MICMD6 (Figura 12f), MHN-UABCS/SR/MICMD7 (Figura 12g), MHN-UABCS/SR/MICMD8 (Figura 12h), MHN-UABCS/ SR/MICMD9 (Figura 12i), MHN-UABCS/SR/MICMD10 (Figura 12j), MHN-UABCS/SR/MICMD11 (Figura 12k), MHN-UABCS/SR/ MICMD12 (Figura 12l) y MHN-UABCS/SR/MICMD13 (Figura 12m). Localidad y edad. Cañón El Álamo (Loc. 5), Calderas El Aguajito y La Reforma, BCS, México. Formación Tirabuzón (Plioceno).

Descripción. Los dientes muestran la heterodoncia sexual (ginándrica), donde los dientes de los machos presentan coronas cuspadas, y los de las hembras se caracterizan por coronas redondeadas o achatadas, aunque presentan una cresta central de lado a lado, que separa las caras labial y lingual. Ambas formas presentan muescas en la cara labial de las coronas. Las raíces son delgadas, bilobuladas, más angostas que las coronas.

Observaciones. El género Dasyatis tiene un registro del Paleoceno al
Plioceno en la península de Baja California (González Barba y Thies, 2000). La morfología dental y la dentición del género son muy variables según la especie. Estos batoides tienen colas más largas que el disco y carecen de aletas dorsales. Se caracterizan por aletas pectorales ubicadas delante del hocico (Cappetta, 2012). El disco es generalmente de forma rómbica, a veces ligeramente redondeado en la región rostral, y la cola larga a menudo tiene forma de látigo. Las rayas de la familia Dasyatidae se encuentran en aguas costeras poco profundas, pudiendo adentrarse en zonas estuarinas, abundan en las regiones subtropicales y tropicales. El género Dasyatis se encuentra en plataformas continentales y se llegan a encontrar en ríos y lagos. Incluye al menos 38 especies recientes (Cappetta, 2012).

\section{Aetobatidae White y Naylor, 2016 Aetobatus Blainville, 1816 Aetobatus sp.}

Ejemplar referido. MHN-UABCS/SR/RA1 (Figura 13a). Localidad y edad. Cañón El Álamo (Loc. 5), calderas El Aguajito y La Reforma, BCS, México. Formación Tirabuzón (Plioceno).

Descripción. MHN-UABCS/SR/RA1 es un fragmento de placa dental que durante la revisión ha sido asignado al género Aetobatus. En la vista apical se aprecia la forma inclinada, que caracteriza estas placas dentales.

Observaciones. El género presenta un registro del Eoceno al Plioceno en la península de Baja California (González Barba y Thies, 2000). Actualmente la mayoría de los géneros pertenecientes a la familia Aetobatidae habitan mares tropicales y cálidos templados, generalmente en aguas someras (Cappetta, 2012). El género Aetobatus frecuentemente habita aguas costeras continentales e insulares. Estas rayas se caracterizan por ser bentónicas, se encuentran en fondos blandos de aguas someras, inclusive en aguas costeras como bahías, lagunas y estuarios; se alimenta de bivalvos y ostras, la especie del Pacífico Oriental Tropical es Aetobatus laticeps Gill, 1865 (White y Last, 2016a).

\section{Myliobatidae Bonaparte, 1838 \\ Myliobatis Cuvier, 1816 Myliobatis sp.}

Ejemplar referido. MHN-UABCS/SR/RM1 (Fig 13B).

Localidad y edad. Cañón El Álamo (Loc. 5), calderas El Aguajito y La Reforma, BCS, México. Formación Tirabuzón (Plioceno).

Descripción. MHN-UABCS/SR/RM1 es una placa dental alargada mesio-distalmente, con la cara apical de la corona de superficie lisa y la raíz multilobulada.

Observaciones. El género presenta un registro del Eoceno al Plioceno en la península de Baja California (González Barba y Thies, 2000). Estas rayas se caracterizan por tener hábitos bentónicos sobre fondos arenosos - fangosos y en mantos de macroalgas de aguas costeras, con profundidades de hasta $46 \mathrm{~m}$ de profundidad. La especie Myliobatis californica (Gill, 1865), es muy común en la fauna de batoideos del Pacifico Oriental Trópical (McEachran y Notarbartolo di Sciara, 1995; White y Last, 2016b).

\section{Rhinopterinae Jordan y Evermann, 1896 Rhinoptera Cuvier, 1829 \\ Rhinoptera sp.}

Ejemplares referidos. MHN-UABCS/SR/RR4 (Figura 13c); MHNUABCS/SR/RR2 (Figura 13d).

Localidad y edad. Cañón El Álamo (Loc. 5), calderas El Aguajito y La Reforma, BCS, México. Formación Tirabuzón (Plioceno). 
a)
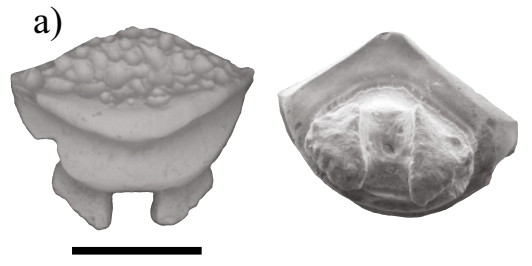

d)
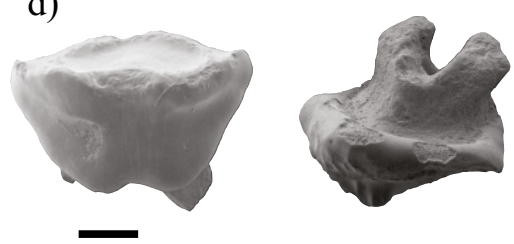

g)
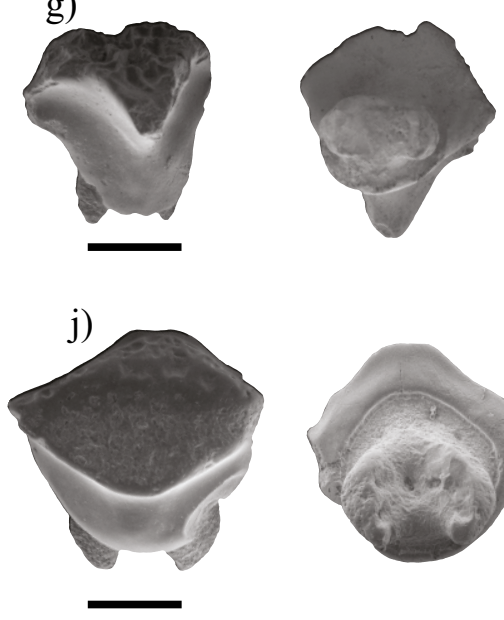

b)

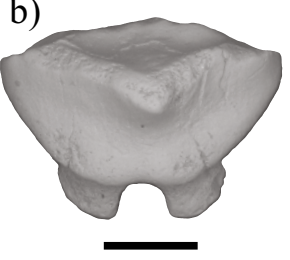

e)

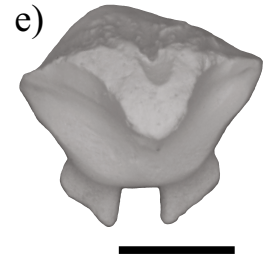

h)

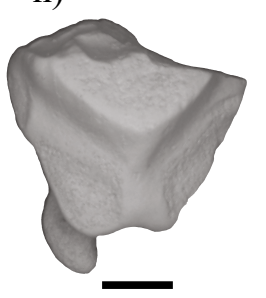

k)
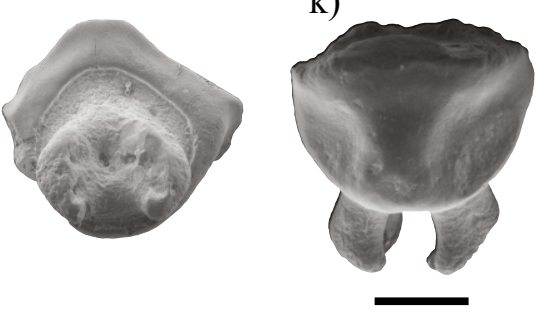
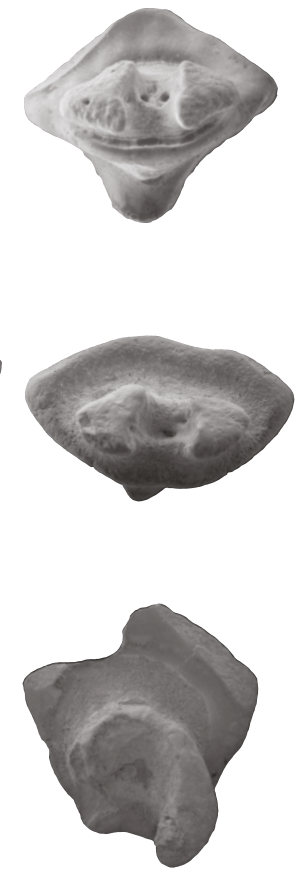

c)
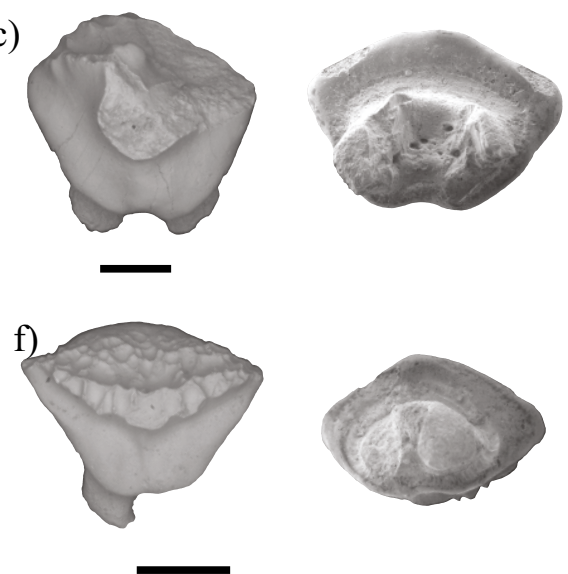

i)
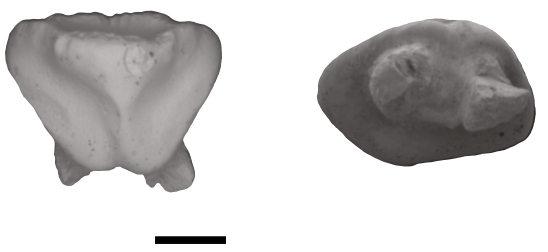

1)
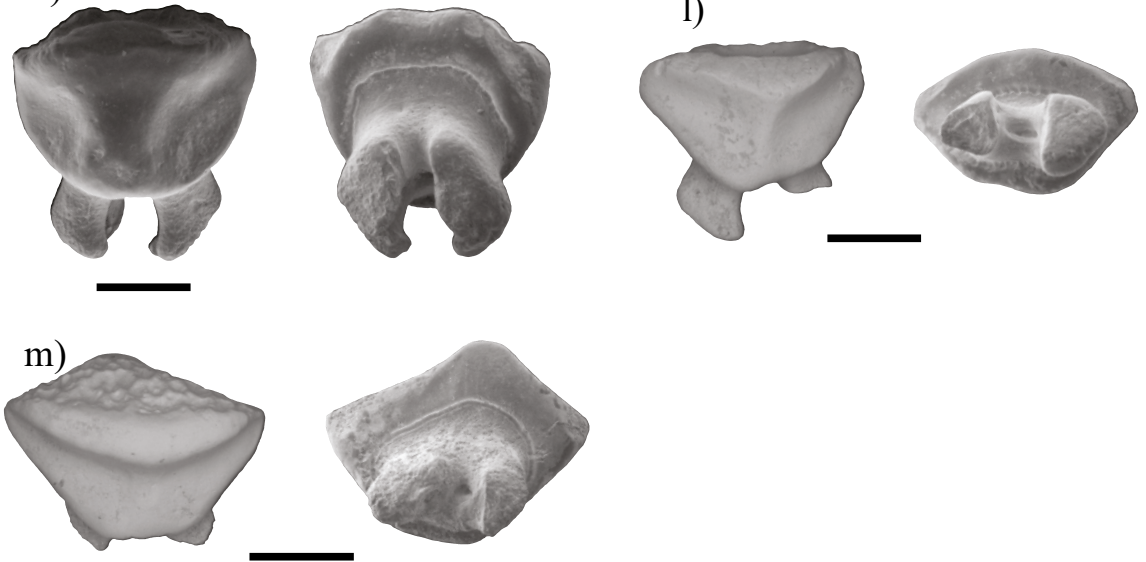

Figura 12. Dientes fósiles de la familia Dasyatidae. a-m) Dasyatis sp. (MHN-UABCS/SR/MICMD1, MHN-UABCS/SR/MICMD2, MHN-UABCS/SR/MICMD3, MHNUABCS/SR/MICMD4, MHN-UABCS/SR/MICMD5, MHN-UABCS/SR/MICMD6, MHN-UABCS/SR/MICMD7, MHN-UABCS/SR/MICMD8, MHN-UABCS/ SR/MICMD9, MHN-UABCS/SR/MICMD10, MHN-UABCS/SR/MICMD11, MHN-UABCS/SR/MICMD12 y MHN-UABCS/SR/MICMD13). Escala igual a 1mm.

Descripción. MHN-UABCS/SR/RR4 y MHN-UABCS/SR/RR2 son dos placas dentales que durante la revisión han sido asignadas a Rhinoptera sp. Las placas dentales presentan un contorno hexagonal, son más delgadas que en Myliobatis, la cara oclusal de la corona es lisa. La raíz es multilobulada.

Observaciones. El género presenta un registro del Eoceno al Plioceno en la península de Baja California (González Barba y Thies, 2000). Las rayas de la familia Rhinopteridae se caracteriza por una dentición de tipo triturador, la cara oclusal de la corona se observa de tipo hexagonal, las placas dentales decrecen en anchura hacia los márgenes y son más gruesos en la zona media que en los laterales (Cappetta, 2012). Las rayas del género Rhinoptera actualmente habitan zonas costeras de la plataforma continental; en la región de Pacifico Oriental Tropical se encuentra la especie R. steindachneri Evermann y Jenkins, 1891 (McEachran y Notarbartolo di Sciara, 1995; Last et al., 2016).
Mobulidae Gill, 1893

Mobula Rafinesque, 1810

Mobula cf. munkiana Notarbartolo di Sciara, 1987

Ejemplar referido. MHN-UABCS/SR/MICMM (Figura 13e).

Localidad y edad. Cañón El Álamo (Loc. 5), calderas El Aguajito y La Reforma, BCS, México. Formación Tirabuzón (Plioceno).

Descripción. MHN-UABCS/SR/MICMM es un diente anterior, que muestra una raíz de tres surcos y crestas, y una corona con tres cúspides fracturadas, que durante la revisión de las morfologías dentales en esta familia en Adnet et al. (2012) ha sido asignado al género Mobula y a la especie M. munkiana.

Observaciones. El género presenta un registro del Mioceno al Plioceno en la península de Baja California (González Barba y Thies, 2000). Las rayas pertenecientes a este género son consideradas pelágicas de aguas 
costeras y oceánicas (McEachran y Notarbartolo di Sciara, 1995). White y Last, (2016c) le llaman raya diablo pigmea y se encuentra restringida al Pacifico Oriental Tropical. Este sería el primer registro para esta especie en la historia del Golfo de California.

\section{DISCUSIÓN}

La presencia de dientes fósiles de tiburón ha sido ampliamente documentada en la cuenca de SR; este tipo de fósiles han sido reportados en capas de la Formación Tirabuzón en la localidad de Corkscrew Hill (Applegate, 1978; Applegate y Espinosa-Arrubarrena, 1981; Carreño, 1981). El contenido fósil de la Formación Tirabuzón ha sido una herramienta importante para determinar el ambiente de depósito y la edad relativa (Plioceno) de la formación y también se ha utilizado para distinguirla de la Formación Infierno (Wilson y Rocha, 1955). Mediante el análisis de los estudios previos, compañas de campo y análisis de la localidad de Corkscrew Hill al norte de la población de Santa Rosalía se logró correlacionar a la Formación Tirabuzón con cinco localidades ubicadas en las calderas de La Reforma y El Aguajito.
Con base en la descripción litológica y fauna de elasmobranquios identificada proponemos extender la distribución geográfica de los afloramientos de la Formación Tirabuzón hasta el cañón El Gringo ubicado en la porción central de la caldera El Aguajito (Figura 14). En cada una de las localidades se levantaron secciones estratigráficas a detalle y se colectaron dientes fósiles de elasmobranquios, incluyendo la localidad de Corkscrew Hill, donde se identificaron estos especímenes para corroborar la correlación estratigráfica, así como la edad relativa de la formación en el área de las calderas. En las seis localidades se encontraron fósiles de dientes de Tiburón, similares a los reportados por Applegate (1978). La localidad más fosilífera después de Corkscrew Hill corresponde al cañón El Álamo (Loc. 5), con 17 especies y dos géneros de tiburones; una especie y seis géneros de raya identificados. En esta última localidad reportamos por primera vez para la cuenca de Santa Rosalía, seis especies de tiburones: Deania cf. Calcea, Heterodontus francisci, Rhincodon typus, Carcharhinus brevipinna, Triakis cf. semifasciata, Galeorhinus sp. cf. G. galeus y dos géneros Squalus sp. y Mustelus sp. También logramos identificar una especie de raya: Mobula sp. cf. M. munkiana y seis géneros Rhinobatos sp., Raja sp., Aetobatus sp., Myliobatis sp., Rhinoptera sp. y Dasyatis sp. En la

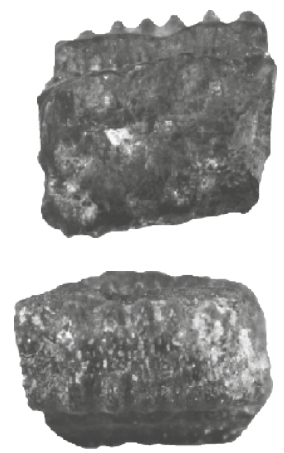

a)
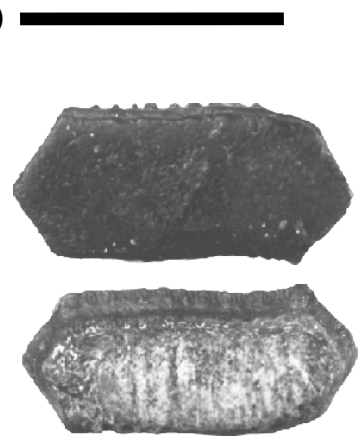

c)

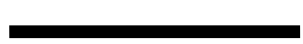

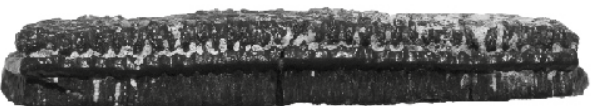
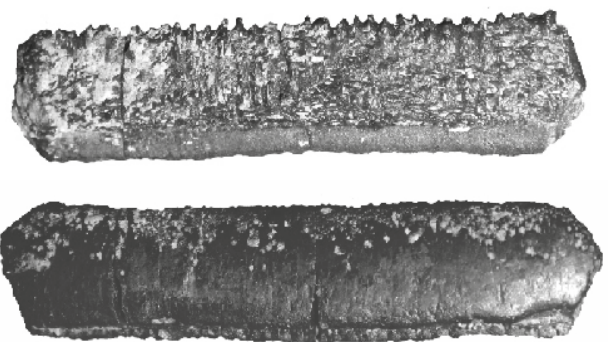

b)

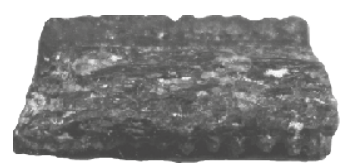

d)
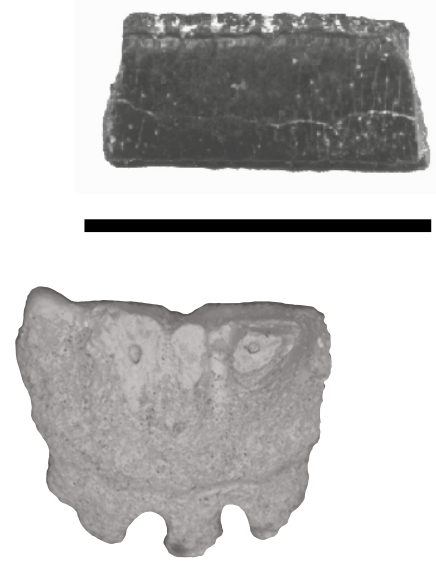

$1 \mathrm{~mm}$ e)

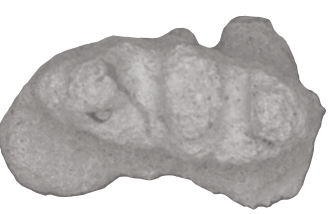

Figura 13. Dientes fósiles de rayas asignados a las familias Myliobatidae, Rhinopteridae y Mobulidae. a) Aetobatus sp. (MHN-UABCS/SR/RA1). b) Myliobatis sp. (MHN-UABCS/SR/RM1). c-d) Rhinoptera sp. (MHN-UABCS/SR/RR4 y MHN-UABCS/SR/RR2). e) Mobula cf. munkiana (MHN-UABCS/SR/MICMM). Escala igual a $1 \mathrm{~cm}$ en a-d y a $1 \mathrm{~mm}$ en e. 


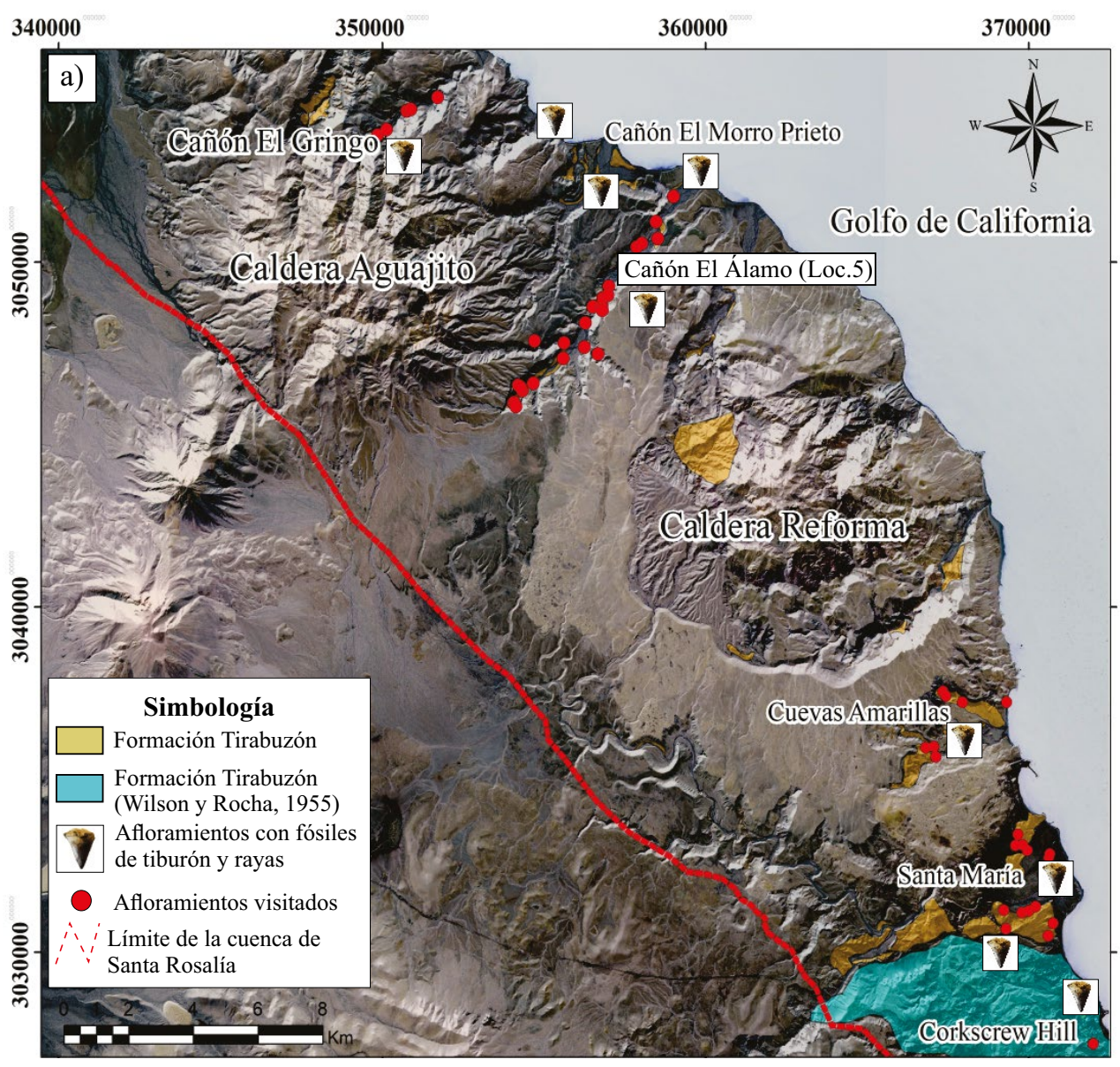

\section{b)}

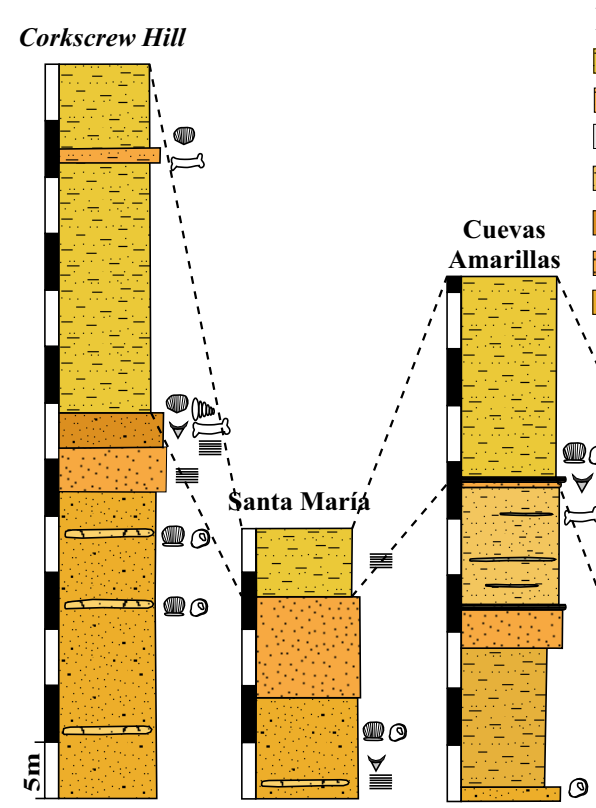

Leyenda

\section{Formación Tirabuzón}

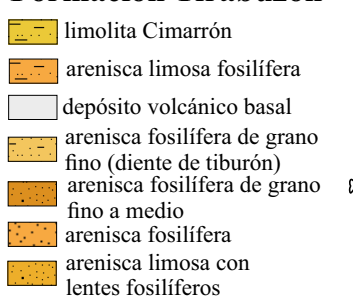

Bivalvos (en su mayoría pectínidos (2) Ostras

$\forall$ Dientes de tiburón y rayas Impresiones de moluscos Moldes internos de moluscos $\Leftrightarrow$ Huesos de mamíferos marinos 竞 Laminación

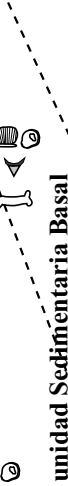
:

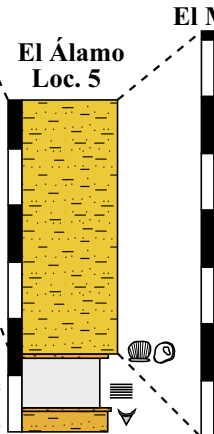

El Morro Prieto

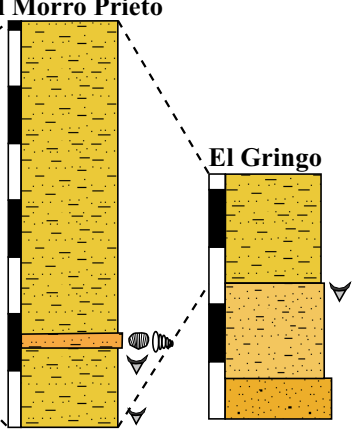

S-Santa Rosalía__Caldera La Reforma Caldera El Aguajito — N

Figura 14. a) Mapa de sitios fosilíferos, afloramientos visitados y extensión de la Formación Tirabuzón. b) Secciones estratigráficas de localidades donde aflora la unidad limolita Cimarrón y donde se encontraron fósiles de dientes de tiburones y rayas. 
localidad de Corkscrew Hill las faunas más significativas identificadas corresponden a: Otodus megalodon (Agassiz, 1843), Hemipristis serra (Agassiz, 1843), Parotodus benedeni (Le Hon, 1871) y Carcharodon carcharias (Figura 15) también reportadas por Applegate (1978). Los tres primeros fósiles pertenecen a especies de megatiburones extintas durante el Neógeno (Plioceno-Pleistoceno) (Capetta, 2012; Pimiento y Clements, 2014). En las secciones de las localidades de Santa María y Cuevas Amarillas localizadas en el borde sur de la Caldera La Reforma y en las secciones de las localidades del cañón del Morro Prieto y cañón El Gringo a 4.5 y 9 km al N del cañón El Álamo, se identificaron las siguientes especies: Himipristis serra, Carcharodon charcharias, Galeocerdo cuvier y Charcharinus obscurus.

\section{Correlación, paleoambiente y edad}

Con base en las características litológicas y el contenido fósil realizamos la correlación de la Formación Tirabuzón a lo largo de la zona de estudio. La presencia de especies extintas en cinco de las localidades fue clave para poder realizar la correlación y poder establecer una edad relativa para la Formación Tirabuzón en el área. La especie Hemipristis serra fue identificada en cinco localidades: Corkscrew Hill, Santa María, Cuevas Amarillas, cañón del Morro Prieto y cañón El Gringo (Figura 16).

H. Serra fue reportado por Applegate (1978) para la localidad de Corkscrew Hill. En general esta especie es considerada cosmopolita y pantropical, su registro es común en afloramientos neríticos con presencia de elasmobranquios tropicales a subtropicales del Mioceno medio al Plioceno (Laurito y Valerio, 2014). Este tiburón se caracteriza por haber habitado plataformas continentales e insulares de mares cálidos (Laurito y Valerio, 2008; Cappetta 2012), muy probablemente con rango de profundidad de 1 a $100 \mathrm{~m}$ (Laurito y Valerio, 2014). En las seis localidades estudiadas se encontraron las especies Carcharodon charcharias, Galeocerdo cuvier y Charcharinus obscurus, las cuales se

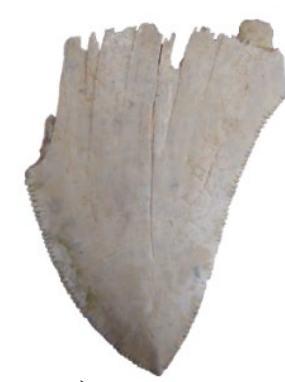

a)

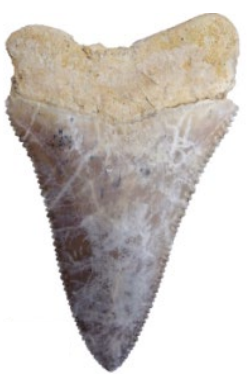

c)

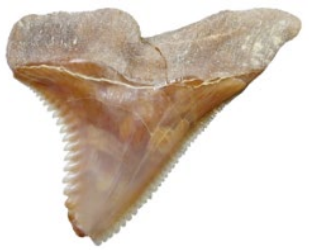

e)

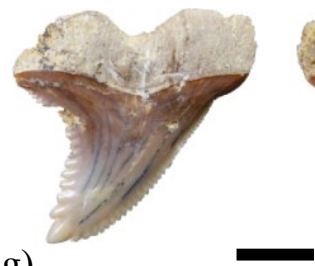

g)
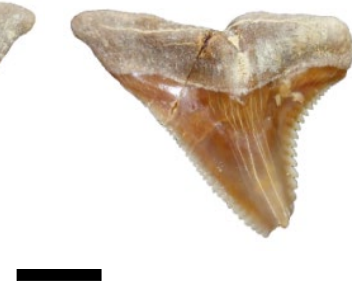

f)

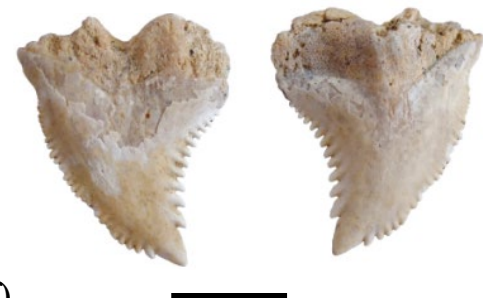

h)

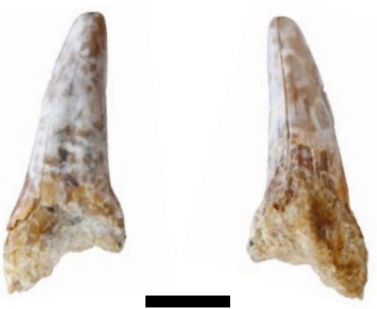

Figura 15. Dientes fósiles encontrados en la localidad de Corkscrew Hill en arenisca que corresponde a la unidad arenisca- limolita naranja. a-b) Otodus megalodon. c) Carcharodon carcharias. d) Parotodus benedeni. e-h) Hemipristis serra. Todos los ejemplares se presentan en vista labial y lingual. La escala corresponde a $1 \mathrm{~cm}$. 
a)
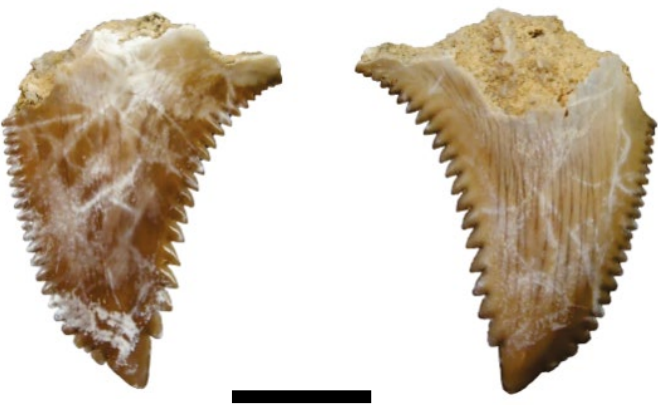

c)

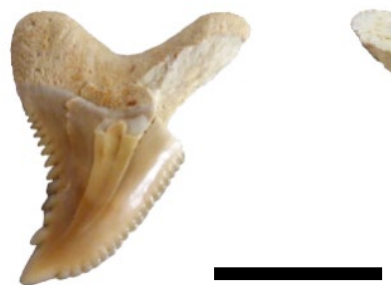

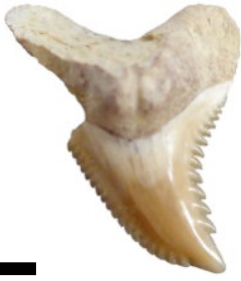

b)
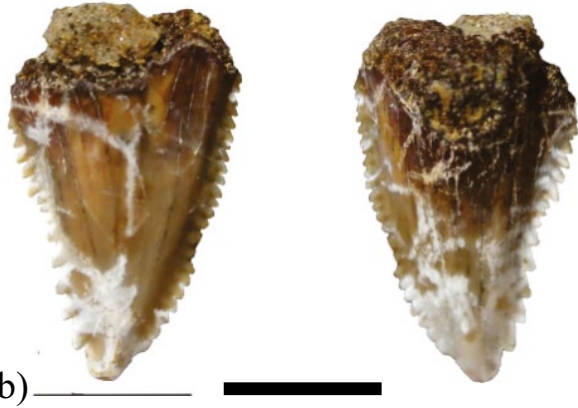

d)

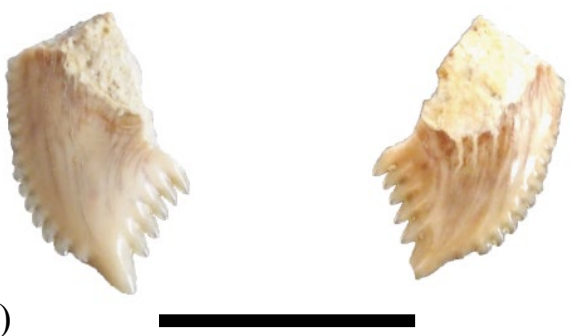

Figura 16. Dientes fósiles de Hemipristis serra encontrados en la unidad arenisca y limolita naranja en diversas localidades del área de estudio. a) Localidad de Santa María. b) Localidad de Cuevas Amarillas. c) Localidad cañón El Morro Prieto. d) Localidad cañón El Gringo. Todos los ejemplares se presentan en vista labial y lingual. La escala corresponde a $1 \mathrm{~cm}$.

caracterizan actualmente por habitar con frecuencia en zonas costeras en mares templados (Compagno, 1984a, 1984b; Compagno, 2001). Las especies C. charcharias y G. cuvier incluso llegan a introducirse en bahías poco profundas, estuarios y zonas intermareales (Compagno, 2001). C. obscurus es un tiburón costero- pelágico, habita desde plataforma continental e insular hasta aguas oceánicas, que abarca desde la zona de oleaje hasta profundidades de $400 \mathrm{~m}$ (Compagno, 1984a, 1984b).

Con base en lo anterior el ambiente de depósito de la Formación Tirabuzón muy probablemente fue de plataforma continental costero, de aguas cálidas tropicales a templadas, corroborado por el ensamble faunístico identificado para el cañón El Álamo (Loc. 5), donde sobresale el género Carcharhinus, con siete especies identificadas, de las cuales cinco: C. albimarginatus, C. brachyurus, C. brevipinna, C. obscurus y C. limbatus se caracterizan por habitar zonas costeras de plataformas continentales en mares tropicales a templados (Compagno, 1984a, 1984b). Finalmente, otra característica de importancia observada en la fauna de la localidad cañón El Álamo (Loc. 5) es la mezcla de organismos adultos y juveniles, evidencia de una zona de crianza como estuarios, lagunas costeras o bahías protegidas.

En cuanto a los aspectos litológicos observados en los afloramientos, la litología más representativa en las seis localidades corresponde a limolita a limolita arenosa de color amarillo ocre a café claro, que nosotros describimos en el cañón El Álamo como la unidad limolita Cimarrón, la cual en el área de estudio corresponde a la cima de la formación Tirabuzón (Figura 17). La limolita se encuentra sobreyaciendo a la arenisca y conglomerado fosilífero que contienen los dientes de elasmobranquios, lo cual se puede observar claramente en las localidades de Corkscrew Hill, Cuevas Amarillas, cañón El Álamo y cañón El Gringo. En las visitas de campo observamos que los afloramientos de la subunidad limolita Cimarrón se extienden por más de 50 kilómetros desde la población de Santa Rosalía hasta la localidad de punta San Carlos al norte de la caldera El Aguajito. La limolita presenta de 25 a $85 \mathrm{~m}$ de espesor, con un promedio de $30 \mathrm{~m}$. Wilson y Rocha (1955) describieron a esta subunidad como la facies de grano fino de la formación, la cual se localizaba en la línea de costa. Sin embargo, nosotros identificamos esta facies en los cañones El Álamo y El Gringo en afloramientos a 9.3 y $5 \mathrm{~km}$ tierra adentro.

Por último, nosotros reportamos la presencia de un pulso volcánico intercalado en la sucesión sedimentaria correspondiente a la Formación Tirabuzón, el cual corresponde a la unidad depósito volcánico basal, que solo aflora en la localidad 5 del cañón El Álamo. Cabe señalar, que para la región de Santa Rosalía no se han reportado evidencias de volcanismo dentro de la Formación Tirabuzón.

\section{CONCLUSIONES}

Las evidencias litológicas y paleontológicas encontradas en la base de la sucesión sedimentaria del Plioceno-Pleistoceno que aflora en el cañón El Álamo, Corkscrew Hill y en cuatro localidades ubicadas en las calderas de Reforma y Aguajito, así como las relaciones estratigráficas que guardan las unidades y las edades radiométricas, nos ha permitido correlacionar las unidades arenisca-limolita naranja, depósito volcánico basal y limolita Cimarrón con la Formación Tirabuzón descrita para la cuenca de Santa Rosalía. Con base en lo anterior corroboramos una edad de Plioceno medio-tardío para la misma. Por último, la presencia de la unidad depósito Volcánico Basal indica que vulcanismo submarino-subaéreo tuvo lugar en la zona de las calderas de La Reforma y El Aguajito por lo menos desde el Plioceno tardío.

\section{AGRADECIMIENTOS}

El presente trabajo forma parte del proyecto P15 del Centro Mexicano de Innovación de Energía Geotérmica (CeMIE Geo) del Fondo de Sustentabilidad Energética del CONACyT (207032). Agradecemos a la técnica Irma Fabiola Mendiola López por el apoyo brindado en el Laboratorio de Análisis de Partículas y Separación de Minerales y al técnico Silvestre Cardona Melchor, encargado del microscopio electrónico del laboratorio de microanálisis del Instituto de Geofísica, Unidad Michoacán (IGUM-UNAM); a Fernanda Jiménez, 

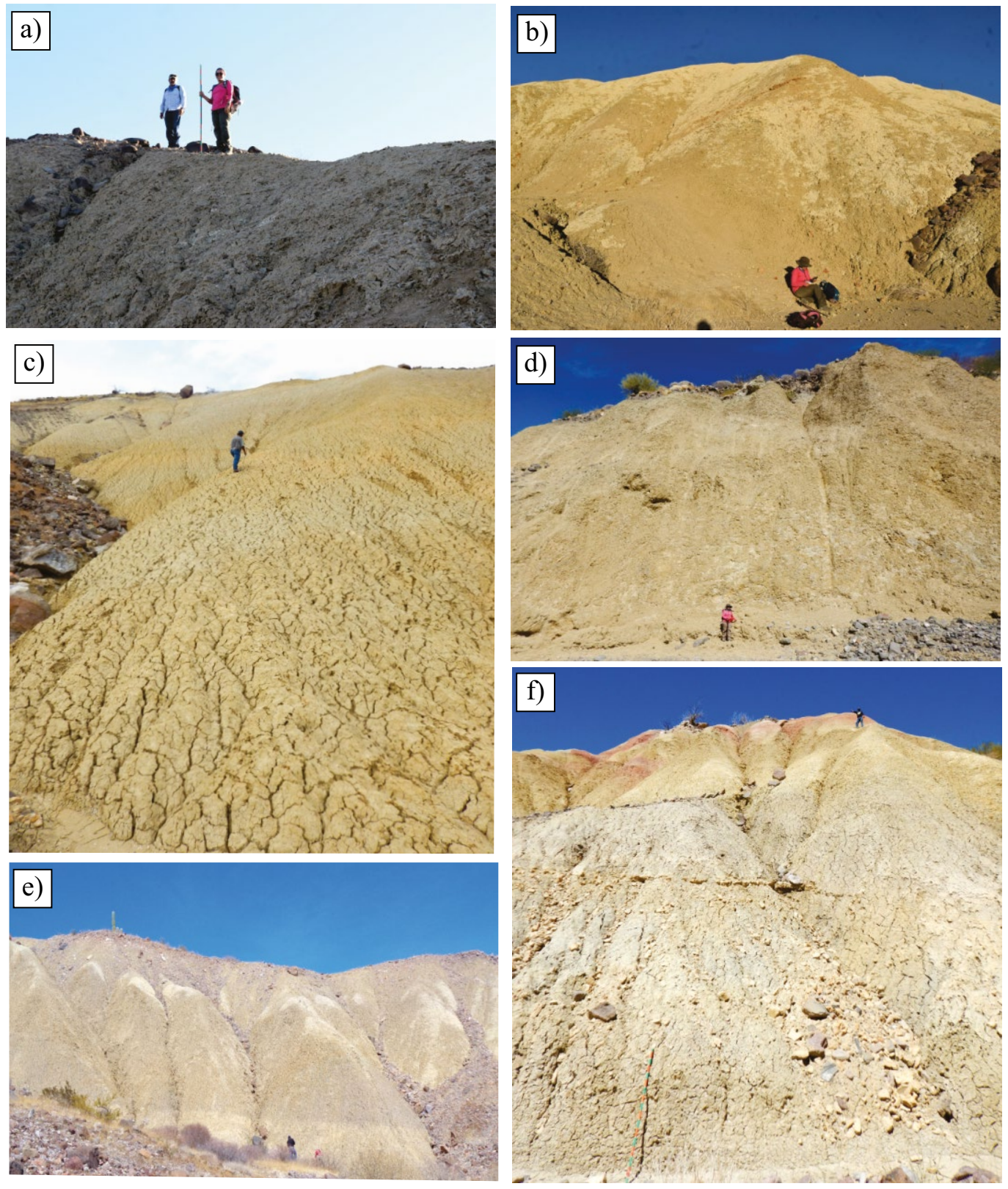

Figura 17. Afloramientos de la unidad limolita Cimarrón a lo largo del área de estudio. a) Localidad de Corkscrew Hill. b, Localidad de Santa María. c) Localidad de Cuevas Amarillas. d) Localidad del cañón El Álamo. e) Localidad cañón El Morro Prieto. f) Localidad cañón El Gringo.

Erick Iván Pacheco Méndez, Francisco Romero, Alfredo Aviña y a Don Miguel Aguilar por su gran apoyo en las campañas de campo; a Rosa Laura Carillo Soledad por el apoyo de limpieza y separación de fósiles; al MC. Oliver Ariel López Conde por la revisión del presente manuscrito y por último a la Dra. Rosario Vázquez Morales, Dr. Armando Carrillo y al Dr. Quentin Edouard Gendron, por su apoyo, sugerencias y comentarios.

\section{REFERENCIAS}

Adnet, S., Cappetta, H., Guinot, G., Notarbartolo di Sciara, 2012, Evolutionary history of devilrays (Chondrichthyes: Myliobatiformes) from fossil and morphological inference: Zoological Journal of Linnean Society, 166, 132-159.
Agassiz L., 1843, Recherches sur les poissons fossils: Neuchatel, Suiza, Imprimerie de Petitpierre, 188 pp.

Alván de la Cruz A., 2008, Geología de Ocucaje: aportes en la sedimentología y paleontología de Lomas de Ullujaya (Ica, Perú): Revista del Instituto de Investigación de la Facultad de Ingeniería Geológica, Minera, Metalúrgica y Geográfica, 11(21), 51-59.

Applegate, S.P., 1972, A revision of the higher taxa of Orectoloboids: Journal of the Marine Biological Association of India, 14(2), 743-751.

Applegate, S.P., 1978, Phyletic Studies; Part 1, Tiger Shark: Universidad Nacional Autónoma de México, Instituto de Geología, Revista, 2(1), 55-64.

Applegate S.P., 1986, The El Cien Formation, strata of Oligocene and Miocene age in Baja California Sur: Universidad Nacional Autónoma de México, Instituto de Geología, Revista, 6(2), 145-162.

Applegate, S.P., Espinosa-Arrubarrena, 1981, The Geology and Selachian Paleontology of Loma del Tirabuzón (Corkscrew Hill), Santa Rosalía, B.C.S., en Ortlieb, L., Roldán-Quintana, J. (ed.), Geology of Northwestern 
Mexico and Southern Arizona, Field Guide and Papers: Universidad Nacional Autónoma de México, Instituto de Geología, 257-263.

Ayres, W.O., 1855, Proceedings of the California Academy of Sciences, ser. 1, v. $1,72-73$.

Ayres, W.O., 1859, Proceedings of the California Academy of Sciences, ser. 1, v. 2, 25-32.

Avellán, D.R., Macías, J.L., Arce, J.L., Jiménez-Haro, A., Saucedo-Girón, R., Garduño-Monroy, V.H., Sosa-Ceballos, G., Bernal, J.P., López-Loera, H., Cisneros, G., Layer,P.W., García-Sánchez, L., Reyes-Agustín, G., Santiago Rocha, V., Rangel, E., 2018, Eruptive chronology and tectonic context of the late Pleistocene Tres Vírgenes vol-canic complex, Baja California Sur (México): Journal of Volcanology and Geothermal Research, 360, 100-125.

Bennett, S.E., Oskin, M.E., Iriondo, A., 2013, Transtensional rifting in the proto-Gulf of California near Bahía Kino, Sonora, México: Geological Society of America Bulletin, 125(11-12), 1752-1782.

Berg, L.S., 1940, Classification of fishes both recen tan fossil: Zoologicheskogo Instituta, 5, 85-517.

Berg, L.S., 1958, System der regenten und fossilen Fischartigen und Fische: Berlin, Deutsch Verlag Wiss, 310 pp.

Blainville, H.M.D., 1816, Prodrome d'une nouvelle distribution systématique du règne animal: Bulletin de Sciences, par la Société Philomatique de Paris, 8: 105-124.

Bleeker, P., 1859, Conspectus systematis Cyprinorum: Natuurkd Tijdschr Neder Indië, 20, 421-441.

Bonaparte, C.L.,1834, Iconografia della fauna Italica per le quatrro classi degli animali vertebrati, Tomo III Pesci: Roma, Tipografia Salviucci, sin paginación.

Bonaparte, C. L., 1838, Selachorum tabula analítica: Nuovi Annali delle Scienze Naturali, 1, 195-214.

Buen, F., 1926, Catalogo ictiológico del Mediterráneo español y de Marruecos, recopilando lo publicado sobre peces de las costas mediterráneas y próximas del Atlántico (Mar de España): Resultados de las Ampafias Realizadas por Acuerdos Internacionales, Instituto Español de Oceanografía, 2, 221 pp.

Cabrera, D.A., Cione, A.L., Cozzuol, M.A., 2012, Shark jaw elements (Elasmobranchii, Squatinidae) from the Miocene of Southern Argentina: Ameghiniana, 49(1), 126-131.

Cappetta, H., 1970, Les Sélaciens du Miocène de la région de Montpellier: Paleovertebrata: Mémoire extraordinaire, Montpellier, 139 pp.

Cappeta, H., 1980, Modification du statut générique de quelques espèces de sèlaciens crètacès et tertiaires: Paleovertebrata, 10, 29-42.

Cappetta, H., 2012, Handbook of Paleoichthyology Chondrichthyes (Mesozoic and Cenozoic Elasmobranchii: Teeth): Hans-Peter Schultze, Munchen, Germany, 512 pp.

Cappetta, H., Cavallo, O., 2006, Les sélaciens du Pliocène de la région d'Alba (Piémont, Italie Nord-Ouest): Rivista Piemontese di Storia Naturale, 27, 33-76.

Cappetta, H., Nolf, D., 1991, Les sélaciens du Pliocène inférieur de Le-Pugetsur-Argens (Sud-Est de la France): Palaeontographica, 218, 49-67.

Carreño, A.L., 1981, Ostrácodos y foraminíferos planctónicos de la loma del Tirabuzón, Santa Rosalía, Baja California Sur, e implicaciones bioestratigráficas y paleoecológicas: Universidad Nacional Autónoma de México, Instituto de Geología, Revista, 5(1), 55-64.

Carrillo-Briceño J. D., González-Barba G., Landaeta M., Nielsen S. N., 2013, Condrictios fósiles del Plioceno Superior de la Formación Horcón, Región de Valparaíso, Chile central: Revista Chilena de Historia Natural, $86,191-206$.

Carrillo-Briceño J. D., Aguilera O. A., Rodríguez F., 2014, Fossil Chondrichthyes from the central eastern Pacific Ocean and their paleoceanographic significance: Journal of South American Earth Sciences, 51, 76-90.

Carrillo-Briceño, J.D., Maxwell, E., Aguilera, O.A., Sánchez, R. y Sánchez Villagra, M.R. 2015. Sawfihes and other elasmobranch assemblages from the Mio-Pliocene of the south Caribbean (Urumaco sequence, Northwestern Venezuela): PloS One 10, 10:1-30.

Castro, J.I., 2011, The sharks of North America: Oxford University Press, 613 pp.

Cigala Fulgosi F., 1986, A deep water elasmobranch fauna from a Lower Pliocene outcropping (Northern Italy), en Uyeno T, Arai R, Taniuchi $\mathrm{T}$ and Matsuura K. (eds), Indo-Pacific fish biology: Proceedings of the Second International Conference on Indo-Pacific fishes, Ichthyological Society of Japan, 133-139.
Compagno, J.L.V., 1973, Interrelationships of living elasmobranchs: Zoological, en Greenwood, P.H., Miles, R.S., Patterson, C. (eds.), Interrelationships of fishes: Zoological Journal of the Linnean Society, 53(1), 1-37.

Compagno, L.J.V., 1984a, FAO Species Catalogue, vol. 4, Sharks of the world An annotated and illustrated catalogue of shark species known to date. Part 1. Hexanchiformes to lamniformes: Rome, Food and Agriculture Organization of the United Nations (FAO), FAO Fisheries synopsis 125, v.4, part 1, 249 pp.

Compagno, L.J.V., 1984b, FAO Species Catalogue, vol. 4, Sharks of the world. An annotated and illustrated catalogue of shark species known to date. Part 2. Carcharhiniformes: Rome, FAO Fisheries synopsis 125, v.4, part 2, 251-655.

Compagno, L.J.V., 2001, Sharks of the world. An annotated and illustrated catalogue of shark species known to date Vol. 2. Bullhead, mackerel and carpet sharks (Heterodontiformes, Lamniformes and Orectolobiformes): Rome, Food and Agriculture Organization of the United Nations (FAO), FAO Species Catalogue for Fishery Purposes, núm. 1, v. 2, 269 pp.

Compagno, L.J.V., 2016, Sharks. en Carpenter, K.E., De Angelis, N. (eds.), The living Marine Resources of the Eastern Central Atlantic: Bivalves, gastropods, hagfishes, sharks, batoid fishes, and chimaeras: FAO Species Identification Guide for Fisheries Purposes, 1123-1336.

Compagno, L.J.V., Dando, M., Fowler, S. L., 2005, Sharks of the world: Nueva York, Princeton University Press, $480 \mathrm{pp}$.

Cuvier, G.,1816, Le Règne Animal distribué d'après son organisation pour servir de base à l'histoire naturelle des animaux et d'introduction à l'anatomie compare, Les reptiles, les poissons, les mollusques et les annelids: Paris, Tome II, Deterville, $532 \mathrm{pp}$.

Cuvier, G., 1829, Le Règne Animal, distribué d'après son organisation, pour servir de base àl'histoire naturelle des animaux et d'introduction à l'anatomie compare: Paris, Nouvelle édition, Tome II, Deterville, $406 \mathrm{pp}$.

Dorsey, R.J., Umhoefer, P.J., 2012, Influence of sediment input and plate-motion obliquity on basin development along an active oblique-divergent plate boundary: Gulf of California and Salton Trough, en Busby, C., Azor, A., (eds.), Tectonics of Sedimentary Basins Recent advances: India, Blackwell Publishing, 209-225, DOI: 10.1002/9781444347166.ch10

Duméril, A.M.C., 1806, Zoologie analytique ou methode naturelle de classification des animaux: Paris, Allais, $344 \mathrm{pp}$.

Ebert, D.A., Fowler, S., Compagno, L., 2016, Sharks of the world: Plymouth, UK, Wild Nature Press, 528 pp.

Ebert, D.A., White, W.T., Goldman, K.J., Compagno, L.J., Daly-Engel, T.S., Ward, R.D., 2010, Resurrection and redescription of Squalus suckleyi (Girard, 1854) from the North Pacific, with comments on the Squalus acanthias subgroup (Squaliformes: Squalidae): Zootaxa. 2612, 22-40.

Evermann, B.W., Jenkins, O.P., 1891, Report upon a collection of fishes made at Guaymas, Sonora, Mexico, with descriptions of new species. Proceedings of the United States National Museum, 14 (846), 121-164.

García-Sánchez, L., Macías, J.L., Sulpizio, R., Osorio-Ocampo, L.S., Pellicioli, C., Pola, A., Avellan, D., Cisneros, G., García, F., Ocampo-Díaz, Y.Z.E., Lira-Beltran, R.M., Saucedo, R., Sánchez-Núñez, J. M., Arce, J.L., CoronaChávez, P., Reyes-Agustin, G., Cardona, M., Layer, P.W., Benowitz, J., Solari, L., Groppelli G., 2019, Geology of La Reforma caldera complex, Baja California, Mexico: Journal of Maps, 15, 487-498.

Garduño-Monroy, V.H., Vargas-Ledezma H., Campos-Enríquez, J.O., 1993, Preliminary geologic studies of Sierra El Aguajito (Baja California, Mexico): a resurgent-type caldera: Journal of Volcanology and Geothermal Research, 59, 47-58.

Gill, T., 1862, Catalogue of the fishes of the eastern coast of North America from Greenland to Georgia: Proceedings of the Academy of Natural Sciences of Philadelphia, $63 \mathrm{pp}$.

Gill T.N., 1864, Second Contribution of Selanchology of California: Proceedings of the Academy of Natural Sciences of Philadelphia, 16, 147-151.

Gill T.N., 1865, Synopsis of the eastern American Shark: Proceedings of the Academy of Natural Sciences of Philadelphia, 16(5), 258-265.

Gill, T.N., 1872, Arrangement of the families of fishes or classes Pisces, Marsipobranchii and Leptocardi: Smithsonian Contributions to Paleobiology, 247, 49.

Gill, T.N.,1893, Families and subfamilies of fishes: Memoirs of the National Academy of Science, 6 (6), 127-138.

Girard, C.F.,1855, Characteristics of some cartilaginous fishes of the Pacific coast of North America: Proceedings of the Academy of Natural Sciences 
of Philadelphia, 7, 196-197.

González-Barba, G., Thies. D., 2000, Asociaciones faunísticas de Condrictios en el Cenozoico de la Península de Baja California, México. Profil Band 18, en XVII Simposio Sobre la geología de Latinoamérica: Sttutgart, Programa y resúmenes, p. 25, Resúmenes extendidos, 27, 1-4.

González-Barba, G., Martínez J. N., 2010, Comparación faunística de tiburones y rayas del Neógeno de Norte y Sur del Perú, en XV Congreso Peruano de Geología, Cusco, Perú.

Gray, J.E.,1851, List of the specimens of fish in the collection of the British Museum, Part I, Chondropterygii: London, British Museum, 160 pp.

Griffith E., Smith C., 1834, The class Pisces, arranged by the Baron Cuvier, with supplementary additions: The animal kingdom, 1, 1-680.

Günther, A., 1870, Catalogue of the fishes in the British Museum: London, British Museum, 8, $549 \mathrm{pp}$

Herman, J., Hovestadt-Euler, M., Hovestadt, D.C., 1988, Contributions to the study of the comparative morphology of teeth and other relevant ichthyodorulites in living superaspecific taxa of Chondrichthyan fishes, Part A: Selachii. No. 2a: Order: Carcharhiniformes - Family: Triakidae: Bulletin de l'Institut Royal des Sciences Naturelles de Belgique, Biologie, $58,99-126$.

Herman, J., Hovestadt-Euler, M., Hovestadt, D.C., 1989, Contributions to the study of the comparative morphology of teeth and other relevant ichthyodorulites in living superaspecific taxa of Chondrichthyan fishes, Part A: Selachii. No. 3: Order: Squaliformes. Families: Echinorhinidae; Oxynatidae and Squalidae: Bulletin de l'Institut Royal des Sciences Naturelles de Belgique, Biologie, 59, 101-157.

Herman, J., Hovestadt-Euler, M., Hovestadt, D.C., 1992, Contributions to the study of the comparative morphology of teeth and other relevant ichthyodorulites in living superaspecific taxa of Chondrichthyan fishes, Part A: Selachii. No. 4: Order: Orectolobiformes. Families: Brachaeliridae, Giglymostomatidae, Hemiscylliidae, Orectolobidae, Parascylliidae, Rhiniodontidae, Stegostomatidae. Order: Pristiophoriformes - Family: Pristiophoridae. Order: Squatiniformes - Family: Squatinidae: Bulletin de l'Institut Royal des Sciences Naturelles de Belgique, Biologie, 62, 193-254.

Herman, J., Hovestadt-Euler, M., Hovestadt, D.C., 1993, Contributions to the study of the comparative morphology of teeth and other relevant ichthyodorulites in living superaspecific taxa of Chondrichthyan fishes, Part A: Selachii. No. 1b: Order: Hexanchiformes - Family: Chlamydoselachidae; No. 5: Order: Heterodontiformes -Family: Heterodontidae; No. 6: Order: Lamniformes - Families: Cetorhinidae, Megachasmidae; Addendum 1 to No. 3: Order Squaliformes; Addendum 1 to No. 4: Order: Orectolobiformes; General Glossary; Summary Part A: Bulletin de l'Institut Royal des Sciences Naturelles de Belgique, Biologie, 63, 185-256.

Holt, J.W., Holt, E.W., Stock, J.M., 2000, An age constraint on Gulf of California rifting from Santa Rosalía basin, Baja California Sur, Mexico: Geological Society of America Bulletin, 112, 540-549.

Jordan, D.S.,1888, A manual of the vertebrate animals of the northern United States, including the district north and east of the Ozark mountains, south of the Laurentian hills, north of the southern boundery of Virginia, and east of the Missouri River; inclusive of marine species: Chicago, 5th Edition, McClurg and Company, 375 pp.

Jordan, D.S., Evermann, B.W., 1896, The fishes of North and Middle America: a descriptive catalogue of the species of fish-like vertebrates found in the waters of North America, north of the Isthmus of Panama. Part I: Bulletin of the United States National Museum, 47, 1-1240.

Jordan, D.S., Gilbert C. H., 1882, Description of four new species of sharks, from Mazatlán, Mexico: Proceedings of the United States National Museum, 5 (268), 102-110.

Jordan, D.S., Snyder, J., 1902, Descriptions of two new species of squaloid sharks from Japan: Proceedings of the United States National Museum, 3 (25), 79-81.

Kent, B.W., 2018, The Cartilaginous Fishes (Chimaeras, Sharks, and Rays) of Calvert Cliffs: Maryland, USA, en Godfrey,S.J. (ed.), The Geology and Vertebrate Paleontology of Calvert Cliffs: Maryland, USA, Smithsonian Contributions to Paleobiology, 45-157.

Kuga, N., 1985, A note of faunal succesion of the tertiary elasmobranchs in Japan: The association for the Geological Colaboration in Japan Monograph, 30, 37-44.

Landini, W., Collareta, A., Di Celma, C., Malinverno, E., Urbina, M., Bianucci,
G., 2019, The early Miocene elasmobranch assemblage from Zamaca (Chilcatay Formation, Peru): Journal of South American Earth Sciences, 91, 352-371.

Last, P.R., White,W.T., Jones, C.M., 2016, Cownose rays Family Rhinopteridae, in Last, P.R., White, W.T., de Carvalho, M.R., Séret, B., Stehmann, M.F.W., Naylor, G.J.P. (eds.): Rays of the World: Australia, CSIRO, 32, 732-740.

Laurito-Mora, C.A., 1999, Los seláceos fósiles de la localidad de Alto Guayacán (y otros ictiolitos asociados), Mioceno Superior-Plioceno Inferior de la formación Uscari, provincia de Limón: Coronado, San José, Costa Rica. CIIPALEOGEO, 127 pp., 44 lám.

Laurito, C.A., Valerio, A.L., 2008, Ictiofauna de la localidad de San Gerardo de Limoncito, Formación Curré, Mioceno Superior, cantón de Coto Brus, provincial de Puntarenas, Costa Rica: Revista Geológica América Central, 39, 65-85.

Laurito, C.A., Valerio, A.L., 2014, Ictiofauna del Mioceno Inferior de la localidad de Pacuare de Tres Equis, Formación Río Banano, provincia de Cartago, Costa Rica, y descripción de un nuevo género y una nueva especie de Scaridae: Revista Geológica de América Central, 50, 153-192.

Le Hon, H.S., 1871, Preliminaires d'un memoire sur les poissons Tertiaires de Belgique: Bruselas, H. Merzbach, 15 pp.

Lesueur, C.A., 1818, Description of several new species of North American fishes: Journal of the Academy of Natural Sciences of Philadelphia, v. 1, parte 1, 222-235.

Lesueur, C.A., 1822, Description of a Squalus of a very large size which was taken on the coast of New Jersey: Journal of the Academy of Natural Sciences of Philadelphia, v. 2, parte 1, 343-352.

Linck, H.F., 1790, Versuch einer Eintheilung der Fische nach den Zähnen: Magazin für das Neueste aus der Physik und Naturgeschichte, 6(3), 28-38.

Linnaeus, C., 1758, Systema naturae per regna tria naturae, secundum classes, ordines, genera, species, cum characteribus, differentiis, synonymis, locis. Laurentii Salvii, Holmiae: Vol. Tomus I, Editio decima, reformata: I-II, $824 \mathrm{pp}$.

Lowe, R.T.,1839, A supplement to a synopsis of the fishes of Madeira: Proceedings of the Zoological Society of London, 7, 76-92.

Marsili, S., 2007, Revision of the teeth of the genus Carcharhinus (Elamosbranchii; Carcharhinidae) from the Pliocene of the Tuscany, Italy: Rivista Italiana di Paleontolgia e Stratigrafia, 113(1), 79-95.

McEachran, J.D., Notarbartolo di Sciara. G., 1995, Peces batoideos, in Fischer, W., Krupp, F., Schnider, W., Sommer, C., Carpenter, K.E., Niem, V.H. (eds.), Guia FAO para la identificación de especies para los fines de la pesca Pacifico Centro-Oriental: Roma, Vol. II Vertebrados, parte 1, FAO, 745-792.

Müller, J., Henle, J., 1837, Gattungen der Haifische und Rochen nach einer von ihm mit Hrn. Henle unternommenen gemeinschaftlichen Arbeit über die Naturgeschichte der Knorpelfische: Akademie der Wissenschaften zu Berlin, 1837(2), 111-118.

Müller, J., Henle, J., 1838, On the generic characters of cartilaginous fishes, with descriptions of new genera: Magazine of Natural History, 2, 88-91.

Müller, J., Henle, J., 1838-41, Systematische Beschreibung der Plagiostomen: Berlin, Veit und Comp., XXII, 200 pp.

Nair, R.V., Lal Mohan, R.S.,1973, On a new deep sea skate, Rhinobatos variegatus, with notes on the deep sea sharks Halaelurus bispidus, Eridacnis radcliffei and Eugaleus omanensis from the Gulf of Mannar: Senckenbergiana Biologica, 54 (1/3), 71-80.

Notarbartolo-di-Sciara, G.,1987, A revisionary study of the genus Mobula Rafinesque, 1810 (Chondrichthyes, Mobulidae) with the description of a new species: Zoological Journal of the Linnean Society, 91(1), 1-91.

Ochoa-Landín, L., Ruiz, J., Calmus, T., Pérez, E., Escandon, F., 2000, Sedimentology and stratigraphy of the Upper Miocene Boleo Formation, Santa Rosalía, Baja California, Mexico: Revista Mexicana de Ciencias Geológicas, 17, 83-95

Ortlieb L.,1981, Sequence of Pleistocene marine terraces in Santa Rosalía area, Baja California Sur, Mexico, in L. Ortlieb J. Roldán (eds.), Geology of northwestern Mexico and southern Arizonc field guides and papers: Instituto de Geología, UNAM, México (Hermosillo), 275-293.

Ortlieb, L., Colletta, B., 1984, Síntesis cronoestratigráfica sobre el Neógeno y el Cuaternario marino de la Cuenca de Santa Rosalía, Baja California Sur, México, en Malpica-Cruz, V., Celis-Gutiérrez, S., Guerrero-García, J., Ortlieb, L. (eds.), Neotectonics and Sea Level Variations in the Gulf 
of California Area, a Symposium, Abstracts: México, D.F., Universidad Nacional Autónoma de México, Instituto de Geología. 242-268.

Oskin, M., Stock, J., 2003, Pacific-North America plate motion and opening of the upper Delfín basin, northern Gulf of California, Mexico: Geological Society of America Bulletin, 115 (10), 1173-1190.

Osorio-Ocampo, S., García-Sánchez, L., Lira-Beltrán, R.M., Macías, J.L., Pola, A., Avellán, D.R., Ocampo-Díaz, Y.Z.E., Groppelli, G., Sulpizio, R., GarcíaTenorio, F., González-Barba, G., Sosa-Ceballos, G., 2019, Volcanic and marine stratigraphy along the El Álamo Canyon, Santa Rosalía Basin, Baja California Sur, en Pearthree, P.A. (ed.), Geologic Excursions in Southwestern North America: Geological Society of America Field Guide 55, 187-208, https://doi.org/10.1130/2019.0055(08)

Pimiento, C., Clements C.F., 2014, ¿When did Carcharocles megalodon become extinct? A new analysis of the fossil record: PLoS ONE 9: e111086.

Poey, F., 1861, XLIX, Poissons de Cuba, espéces nouvelles L. Conspectus piscium Cubensium, en Memorias sobre la historia natural de la Isla de Cuba: La Habana, Cuba, Imprenta de la Viuda de Barcina y Compa., 2(3), 357-404.

Poey, F., 1868, Synopsis piscium Cubensium. Catálogo Razonado de los peces de la isla de Cuba, en Repertorio Físico-Natural de la Isla de Cuba: La Habana, Cuba, Imprenta de la Viuda de Barcina y Compa., 2, 279-484.

Purdy R.W., Schneider VP., Applegate S.P., McLellan J.H., Meyer R.L., Slaughter B.H., 2001, The Neogene shark, ray and bony fishes from Lee Creek Mine, Aurora, North Carolina, en Ray, C.E., Bohasha, D.J. (eds), Geology and Paleontology of the Lee Creek Mina, North Carolina, III: Smithsonian Contribution to Paleobiology. 90, 71-202.

Rafinesque, C.S., 1810, Indice d'ittiologia siciliana; ossia, catalogo metodico dei nomi latini, italiani, e siciliani dei pesci, che si rinvengono in Sicilia disposti secondo un metodo naturale e seguito da un appendice che contiene la descrizione de alcuni nuovi pesci siciliani: Presso Giovanni del Nobolo, Messina, 70 pp.

Risso A., 1810, Ichthylogie de Nice ou historie naturelle des poisons du department des Alpes Maritimes: Paris, F. Schoell, 388 pp.

Risso, A., 1826, Histoire naturelle des principales productions de l'Europe meridionale et particulierement de celles des environs de Nice et des Alpes maritimes: Paris and Strasbourg, XVI, Vol.III, 486 pp.

Rüppell, W.P.E.S.E., 1837, Neue Wirbelthiere zu der Fauna von Abyssinien gehörig: Fische des rothen Meeres: Frankfurt am Main, 1837, 53-80.

Sánchez-Villagra, M.R., Burnham, R.J., Campbell D.C., Feldmann R.M, Gaffney E.S., Kay R.F., Lozsán R., Purdy R.W., Thewissen G.M., 2000, A new nearshore marine fauna and flora from the Early Neogene of Northwestern Venezulea: Journal of Paleontology, 74, 957-968, https://doi.org/10.1017/ S0022336000033126

Scudder, S.J., Simons, E.H., Morgan, G. S.,1995, Chondrichthyes and osteichthyes from the Early Pleistocene Leisey Shell Pit local fauna, Hillsborough Country, Florida: Bulletin of the Florida Museum of Natural History, 37, 251-272.

Smith, A., 1829, Contributions to the natural history of South Africa: Zoology Journal, 16, 443-444.

Smith, A., 1838, On the necessity for a revision of the groups included in the Linnean genus Squalus: The Annals and Magazine of Natural History, $1,72-74$.

Snodgrass, R.E., Heller, E., 1905, Shore fishes of the Revillagigedo, Clipperton, Cocos and Galapagos islands: Proceedings of the Washington Academy of Sciences, v. 6, 333-427.
Springer, S., 1940, Three new sharks of the genus Sphyrna from the Pacific coast of tropical America: Stanford Ichthyological Bulletin, 1 (5), 161-172.

Springer, S., 1950, A revision of North American sharks allied to the genus Carcharhinus: American Museum Novitates, 1451, 1-13.

Valenciennes, A., 1839, Ichthyologie des îles Canaries, ou histoire naturelle des poissons rapportés par Mm.P-B.Webb et S. Berthelot, en Barker-Webb, P., Berthelot, S., Histoire naturelle des îles Canaries (1836-1844): Paris, Béthune éditeur, tomo 2, parte 2, $109 \mathrm{pp}+26$ láminas.

Verma, S.P., Pandarinath, K., Santoyo, E., González-Partida, E., TorresAlvarado, I., Tello-Hinojosa, E., 2006, Fluid chemistry and temperatures prior to exploitation at the Las Tres Vírgenes geothermal field, Mexico: Geothermics 35, 156-180.

Viggiano-Guerra, J.C., Sandoval-Medina, F., Flores-Armenta, M.C., Pérez, R.J., González-Partida, E., 2009, Application of SPCALC for the chemical and thermodynamic fluidal speciation: case study for the wells LV-4A, LV-11 and LV-13 from the Las Tres Vírgenes geothermal field, BCS: Geotermia $22(1), 12-27$

White, W.T., Naylor, G.J. 2016, Resurrection of the family Aetobatidae (Myliobatiformes) for the pelagic eagle rays, genus Aetobatus: Zootaxa, 4139(3), 435-8, https://doi.org/10.11646/zootaxa.4139.3.10

White, W.T., Last, P.R., 2016a, Devilrays Family Mobulidae, en Last, P.R., White, W.T., de Carvalho, M.R., Séret,B., Stehmann, M.F.W., Naylor, G.J.P. (eds.), Rays of the World: Australia, CSIRO, 33, 741-749.

White, W.T., Last, P.R. 2016b, Eagle rays Family Myliobatidae, en Last, P.R., White, W.T., de Carvalho, M.R., Séret,B., Stehmann, M.F.W., Naylor, G.J.P. (eds.), Rays of the World: Australia, CSIRO, 30, 706-725.

White, W.T., Last, P.R. 2016c, Pelagic Eagle rays Family Aetobatidae, en Last, P.R., White, W.T., de Carvalho, M.R., Séret,B., Stehmann, M.F.W., Naylor, G.J.P. (eds.), Rays of the World: Australia, CSIRO, 31, 726-731.

Whitley, G.P., 1929, Additions to the check-list of the fishes of New South Wales. No. 2: Australian Zoologist, 5(4), 353-357.

Whitley, G.P.,1940, The fishes of Australia. Part 1. The sharks, rays, devil fishes and other primitive fishes of Australia and New Zealand. Sydney: Royal Zoological Society of New South Wales, $230 \mathrm{pp}$.

Wilson I. F., 1948, Buried topography, initial structures and sedimentation in Santa Rosalía area, Baja California, Mexico: Bulletin of the American Association of Petroleum Geologists, 32(9), 1762-1807.

Wilson, I.F., Veytia, M., 1949, Geology and manganese deposits of the Lucifer district northwest of Santa Rosalía, Baja California, Mexico: Washington D.C., United States Department of the Interior, Geological Survey, Bulletin 960-F, 177-231.

Wilson, I.F., Rocha, V.S., 1955, Geology and Mineral Deposits of the Boleo Copper District Baja California, Mexico: Washington D.C., United States Geological Survey, Professional Paper 273, 134.

Manuscrito recibido: abril 23, 2019

Manuscrito recibido: septiembre 19, 2019

Manuscrito aceptado: octubre 8, 2019 
FE DE ERRATAS -ERRATUM

Errata a Fauna de tiburones y rayas de la Formación Tirabuzón (Plioceno) en el Cañón El Álamo, sierras de La Reforma - El Aguajito, Baja California Sur, México

[Rev. Mex. Cienc. Geol., 37-1 (2020), 40-63]

\section{R. Marcela Lira-Beltránn 1,*, Gerardo González-Barba ${ }^{2}$, José Luis Macías ${ }^{3}$, Azucena Solis-Añorve², Felipe García-Tenorio ${ }^{3}$, Laura García-Sánchez ${ }^{1}$ y Susana Osorio-Ocampo ${ }^{1}$}

${ }^{1}$ Posgrado en Ciencias de la Tierra, ENES Morelia, Universidad Nacional Autónoma de México,

Antigua Carretera a Pátzcuaro No.8701, Ex Hacienda de San José de la Huerta, C.P. 58190, Morelia, Michoacán, México.

${ }^{2}$ Museo de Historia Natural, Universidad Autónoma de Baja California Sur,

Carretera al sur Km. 5.5, Colonia El Calandrio, C.P. 23080, La Paz, B.C.S., México.

${ }^{3}$ Instituto de Geofísica, Unidad Michoacán, Universidad Nacional Autónoma de México,

Antigua Carretera a Pátzcuaro No.8701 Col. Ex Hacienda de San José de la Huerta, C.P.58190 Morelia, Michoacán, México.

*marcelalirabeltran@gmail.com

En el artículo indicado arriba se omitieron de modo no intencionado las Tablas 1 y 2.

Estas tablas se reproducen continuación y han sido anexadas al artículo original.

Los editores lamentan la omisión.

In the above article, Tables 1 and 2 was unintentionally omitted.

This tables appears $n$ the next page and also has been attached to the original paper.

The publishers apologize for the oversight.

Lira-Beltrán, R.M., González-Barba, G., Macías, J.L., Solis-Añorve, A., García-Tenorio, F., García-Sánchez, L., Osorio-Ocampo, S., 2021, Errata a Fauna de tiburones y rayas de la Formación Tirabuzón (Plioceno) en el Cañón El Álamo, sierras de La Reforma - El Aguajito, Baja California Sur, México [Rev. Mex. Cienc. Geol., 37-1 (2020), 40-63]: Revista Mexicana de Ciencias Geológicas, v. 38, núm. 2, p. 150-151. 
Tabla 1. Elasmobranquios reportados para la cuenca de Santa Rosalía (localidad de Corkscrew Hill) modificado de Applegate (1978).

\begin{tabular}{|c|c|c|}
\hline & Nombre Científico & Estatus actual \\
\hline 1 & Hexanchus griseus (Bonnaterre, 1788) & No reportado en el Golfo de California. \\
\hline 2 & Notorynchus (Ayres 1855) & No reportado en el Golfo de California. \\
\hline 3 & Heterodontus sp. (Blainville, 1816) & Algunas especies viven actualmente en el Golfo de California. \\
\hline 4 & Squalus sp. (Linnaeus, 1758) & No reportado en el Golfo de California. \\
\hline 5 & Odontaspis ferox (Risso, 1810) & Extinto \\
\hline 6 & Parotodus benedeni (Le Hon, 1871) & Extinto \\
\hline 7 & Isurus oxyrinchus (Rafinesque, 1810) & Común en el Golfo de California. \\
\hline 8 & Otodus megalodon (Agassiz, 1843) & Raro en el depósito. Extinto \\
\hline 9 & Carcharodon sulcidens (Agassiz, 1843) & Común en el depósito. Extinto \\
\hline 10 & Carcharodon carcharias (Linnaeus, 1758) & Presente en el Golfo de California. \\
\hline 11 & Cetorhinus sp. (Blainville, 1816) & Raro en el Golfo de California. \\
\hline 12 & Rhizoprionodon longurio (Jordan y Gilbert, 1882) & Común en el Golfo de California. \\
\hline 13 & Sphyrna zygaena, (Linnaeus, 1758) & Presente en el Golfo de California. \\
\hline 14 & Sphyrna lewini (Griffith y Smith, 1834) & Presente en el Golfo de California. \\
\hline 15 & Sphyrna tiburo (Linnaeus, 1758) & Presente en el Golfo de California. \\
\hline 16 & Sphyrna media (Springer, 1940) & Presente en el Golfo de California. \\
\hline 17 & Sphyrna mokarran (Rüppell, 1837) & Presente en el Golfo de California. \\
\hline 18 & Prionace glauca (Linnaeus, 1758) & No reportado en el Golfo de California. \\
\hline 19 & Hemipristis serra, (Agassiz, 1843) & Extinto \\
\hline 20 & Galeocerdo cuvier (Peron y Lesueur, 1822) en Lesueur (1822) & Presente en el Golfo de California. \\
\hline 21 & Carcharhinus leucas (Valenciennes, 1839) & Presente en el Golfo de California. \\
\hline 22 & Carcharhinus obscurus (Lesueur, 1818) & Común en el Golfo de California. \\
\hline 23 & Carcharhinus brachyurus (Günther, 1870) & Presente en el Golfo de California. \\
\hline 24 & Carcharhinus falciformis (Müller Henle, 1839) & Presente en el Golfo de California. \\
\hline 25 & Carcharhinus galapagensis (Snodgrass y Heller, 1905) & Presente en el Golfo de California. \\
\hline 26 & Carcharhinus albimarginatus (Rüppell, 1837) & Presente en el Golfo de California. \\
\hline 27 & Nasolamia velox (Gilbert, 1898) & Presente en el Golfo de California. \\
\hline 28 & Carcharhinus limbatus (Müller y Henle, 1839) & Presente en el Golfo de California. \\
\hline 29 & Carcharhinus altimus (Springer, 1950) & Presente en el Golfo de California. \\
\hline
\end{tabular}

Tabla 2. Elasmobranquios del Cañón El Âlamo (Loc. 5).

\begin{tabular}{|c|c|}
\hline & Nombre Científico \\
\hline 1 & Deania cf. Calcea Lowe, 1839 \\
\hline 2 & Squalus sp. Linnaeus, 1758 \\
\hline 3 & Squatina californica Ayres, 1859 \\
\hline 4 & Heterodontus francisci Girard, 1855 \\
\hline 5 & Rhincodon typus Smith, 1829 \\
\hline 6 & Carcharodon carcharias Linnaeus, 1758 \\
\hline 7 & Triakis $\mathrm{cf}$ semifasciata Girard, 1855 \\
\hline 8 & Galeorhinus galeus, Linnaeus, 1758 \\
\hline 9 & Mustelus sp. Linck, 1790 \\
\hline 10 & Galeocerdo cuvier Peron y Lesueur, 1822, en Lesueur, 1822 \\
\hline 11 & Rhizoprionodon longurio Jordan y Gilbert, 1882 \\
\hline 12 & Carcharhinus albimarginatus Rüppell, 1837 \\
\hline 13 & Carcharhinus brevipinna Müller y Henle, 1839 \\
\hline 14 & Carcharhinus leucas Müller and Henle, 1839 \\
\hline 15 & Carcharhinus longimanus Poey, 1861 \\
\hline 16 & Carcharhinus obscurus Lesueur, 1818 \\
\hline 17 & Carcharhinus limbatus Müller y Henle, 1839 \\
\hline 18 & Negaprion brevirostris Poey, 1868 \\
\hline 19 & Sphyrna zygaena Linnaeus, 1758 \\
\hline 20 & Rhinobatos sp. Linck, 1790 \\
\hline 21 & Raja sp. Linnaeus, 1758 \\
\hline 22 & Dasyatis sp. Rafinesque, 1810 \\
\hline 23 & Aetobatus sp. Blainville, 1816 \\
\hline 24 & Myliobatis sp.Cuvier, 1816 \\
\hline 25 & Rhinoptera sp.Cuvier, 1829 \\
\hline 26 & Mobula cf. munkiana Rafinesque, 1810 \\
\hline
\end{tabular}

